\title{
Associative representational plasticity in the auditory cortex: A synthesis of two disciplines
}

\author{
Norman M. Weinberger \\ Center for the Neurobiology of Learning and Memory, and Department of Neurobiology and Behavior, University of California, \\ Irvine, California 92697-3800, USA
}

\begin{abstract}
Historically, sensory systems have been largely ignored as potential loci of information storage in the neurobiology of learning and memory. They continued to be relegated to the role of "sensory analyzers" despite consistent findings of associatively induced enhancement of responses in primary sensory cortices to behaviorally important signal stimuli, such as conditioned stimuli (CS), during classical conditioning. This disregard may have been promoted by the fact that the brain was interrogated using only one or two stimuli, e.g., a $\mathrm{CS}^{+}$sometimes with a $\mathrm{CS}^{-}$, providing little insight into the specificity of neural plasticity. This review describes a novel approach that synthesizes the basic experimental designs of the experimental psychology of learning with that of sensory neurophysiology. By probing the brain with a large stimulus set before and after learning, this unified method has revealed that associative processes produce highly specific changes in the receptive fields of cells in the primary auditory cortex (Al). This associative representational plasticity (ARP) selectively facilitates responses to tonal CSs at the expense of other frequencies, producing tuning shifts toward and to the CS and expanded representation of CS frequencies in the tonotopic map of Al. ARPs have the major characteristics of associative memory: They are highly specific, discriminative, rapidly acquired, exhibit consolidation over hours and days, and can be retained indefinitely. Evidence to date suggests that ARPs encode the level of acquired behavioral importance of stimuli. The nucleus basalis cholinergic system is sufficient both for the induction of ARPs and the induction of specific auditory memory. Investigation of ARPs has attracted workers with diverse backgrounds, often resulting in behavioral approaches that yield data that are difficult to interpret. The advantages of studying associative representational plasticity are emphasized, as is the need for greater behavioral sophistication.
\end{abstract}

This review presents an account of research on neurophysiological plasticity in the primary auditory cortex (A1), focusing on the issues of associativity and specificity. Related reviews of greater breadth and different emphasis are available (Palmer et al. 1998; Edeline 2003; Ohl et al. 2003; Rauschecker 2003; Weinberger 2004a). Consideration of perceptual learning, which involves prolonged, increasingly difficult frequency discrimination training to reduce the difference limen, is beyond the scope of this review (see, e.g., Goldstone et al. 1997; Gilbert et al. 2001; Moore et al. 2003; Pleger et al. 2003; Brown et al. 2004; Hawkey et al. 2004; Polley et al. 2006). However, we consider associative learning to be fundamental to perceptual learning because, at a minimum, subjects must first learn an association between an acoustic stimulus and a reinforcer; and second, they must learn an association between an instrumental response and a reinforcer, contingent on the acoustic stimulus.

A central goal of this paper is to demonstrate how a synthesis of approaches from the traditionally separate disciplines of sensory neurophysiology and the experimental psychology of learning can illuminate fundamental issues in the neurobiology of learning and memory in general, and the neural substrates of associative processes in particular. Chief among these is the question of neural representations of sensory/perceptual events, such representations being widely thought to constitute core elements that become associated in learning.

It may seem strange to some readers that sensory neurophysiology could play a critical role in attacking central issues in brain substrates of learning/memory. After all, research in this field has been dominated and remarkable progress has been

E-mail nmweinbe@uci.edu; fax (949) 824-4576.

Article published online in January 2007. Article and publication date are at http://www.learnmem.org/cgi/doi/10.1101/lm.421807. made by concentrating on structures such as the cerebellum, amygdala, striatum, hippocampus, medial temporal lobe, frontal, cingulate, and other nonsensory cortical regions. Moreover, most basic knowledge of the workings of sensory systems, particularly the auditory, somatosensory, and visual systems, has been garnered from animals under deep general anesthesia, the state that is most inimical to new learning. Thus, it has been concluded, usually implicitly, that sensory systems, while very complex and perhaps even elegant, are limited to providing detailed information about the outside world, in a sense supplying the "raw materials" for learning and memory. But, they are viewed as neither critical sites of processes enabling learning nor the loci of memory storage.

Research, especially during the past $15 \mathrm{yr}$, has directly challenged traditional views that essentially excluded sensory systems from an active and likely critical role in learning and memory. Most relevant research comes from work on the auditory system, particularly on the primary auditory cortex, to which we will now turn. However, importantly, much of this very recent and currently burgeoning area of inquiry emanates from workers whose major training has been in sensory neurophysiology rather than in learning and memory. Therefore, it is necessary to encourage the use of accepted and valid concepts and methods from the field of learning/memory. Of course, the converse holds for researchers whose training has been in learning; their use of appropriate methods from the field of sensory physiology is equally important. These issues will be discussed later. But first, it will be helpful to consider why sensory systems in general, and the auditory cortex in particular, have been largely ignored in the neurobiology of learning and memory. In fact, they are among the very last brain systems admitted to this field. 


\section{Background}

The auditory cortex was delineated by ablation work in animals during the latter part of the 19th century (Diamond 1985). The "gold standard" was a demonstration of crudely assessed deafness, understandable given the technical limitations of the times. With the advent of electrophysiology in the 1920s-1930s, it became possible to seek cortical regions that responded (evoked potentials) to sound, and eventually to successfully demarcate A1 and its cochleotopic and tonotopic frequency organization (e.g., Tunturi 1944). However, in 1906, long before the physiological identification of auditory cortical fields, Campbell had published a landmark study of cortical cytoarchitectonics of the human and some animals. He sought structural-functional relationships and essentially asserted them on anatomical grounds. While perhaps not the first worker to use the terms "sensory" and "psychic" cortex, his influence was profound. Campbell labeled the cytoarchitectonic region now identified as primary auditory cortex (A1) "auditory sensory," and called auditory regions nearby (now often called auditory "belt" areas [Kaas and Hackett 2000]) as "auditory psychic." In this, Campbell intended and made a clear distinction between cortical regions he considered to be purely sensory from those he believed to concern the understanding or comprehension of sounds. His implicit assumption was one of strictly hierarchical cortical functional architecture, with what are now referred to as "cognitive functions" dependent upon input from "sensory" structures. This conceptual schema still has strong resonance today. The late Irving Diamond, a major contributor to the anatomical and behavioral understanding of thalamic and cortical levels of the neuraxis, insightfully held that Campbell's monograph was instrumental in removing learning and memory from primary sensory cortices (Diamond 1985).

Following World War II and continuing to the present, auditory neurophysiology expanded greatly. The coding of acoustic parameters by single neurons and groups of cells in many species has yielded the functional organization of auditory fields adjacent to A1 and refinement of the latter's tonotopic organization as well as providing insights into other stimulus domains, e.g., binaural interactions, bandwidth (sharpness of tuning), temporal and spectral modulations, etc.

However, during the 30-yr span from the mid-1950s to the mid-1980s there was a little-noted parallel line of inquiry into associative learning and the auditory cortex. In 1956, Galambos et al. (1956) published the first electrophysiological study of the auditory cortex during learning. They found that classical conditioning (click-shock pairing) in the cat was accompanied by significant increases in the amplitude of A1-evoked potentials to the conditioned stimulus (CS). Interestingly, these investigators included a "sensory physiology" control, i.e., showed that increased amplitude was not due to inadvertent increased CS sound level (intensity), due to relaxation of the middle-ear muscles or other factors, by the use of neuromuscular blockade. But they did not use controls for nonassociative factors, such as sensitization. Subsequently, scores of similar studies were performed in a variety of species (including humans), with the addition of nonassociative controls, the extension of evoked potential recordings to clusters of neurons and single-cell recordings, the use of twotone discrimination protocols and the employment of instrumental conditioning tasks, and appetitive as well as aversive reinforcements. Overall, the findings clearly established that associative processes were responsible for increased responses of A1 to $\mathrm{CS}$ and $\mathrm{CS}^{+}$; responses to $\mathrm{CS}^{-}$stimuli did not increase as much or at all, and often decreased (Weinberger and Diamond 1987).

In toto, such plasticity in A1 attracted scant attention, even within the neurobiology of learning and memory. Without de- tailed historical study, the reasons for this neglect can only be the subject of speculation. Several factors come to mind. First, there was the discovery that patient H.M., having received bilateral excisions of medial temporal lobe structures, could not retain new facts. In its understandably exuberant expansion, subsequent research focused on structures that appeared to be essential for memory, such as the hippocampus. Second, there was no conceptual framework within which to incorporate the findings of associative plasticity in A1, particularly as most models of brain and learning restricted sensory cortices to the status of stimulus analyzers. (The same consideration applied to the occasional reports of similar findings in the primary somatosensory and visual cortices.) Third, workers in learning and memory had no vested interest in sensory systems, and therefore were not concerned that the research initiated by Galambos and colleagues disproved the view that sensory systems responded to sensory parameters, not "psychological" parameters such as the acquired behavioral significance of a stimulus.

Neglect from auditory neurophysiologists might seem particularly unexpected. After all, a major implication of the fact that associative processes systematically modify the responses of A1 to physically constant sounds is that such neural responses appear to be inherently ambiguous. For example, an increase in response magnitude might be due either to an increase in stimulus level, an increase in its behavioral significance, or both. My conjecture here is that the learning/memory findings seemed to have little relevance for sensory physiology, because the auditory stimuli used were too limited to be of any interest. Thus, standard conditioning studies used a single acoustic CS and discrimination studies used only two, a $\mathrm{CS}^{+}$and a $\mathrm{CS}^{-}$. However, the concept of the receptive field is fundamental to sensory physiology; no sensory physiologist would attempt to describe the response properties of a cell with such a restricted stimulus set. Moreover, the conditioning studies did not even provide information on the relationship between the tone used as the CS and the best frequency (peak of the spectral tuning curve) or the characteristic frequency (frequency of response at threshold). Finally, singleunit conditioning studies in the 1970s and early 1980s invariably reported that a certain proportion of A1 cells increased their discharges, while another proportion decreased their discharges. While these effects were shown to be associative, they made little functional sense. Therefore, from the viewpoint of auditory physiology, the changes in cortical responses during learning were essentially not interpretable.

Our own studies of single cells in both A1 and the little understood adjacent "secondary field" (A2), while adding some new wrinkles to the discourse on associative processes (Diamond and Weinberger 1984b; Weinberger et al. 1984b), found similar mixed effects and convinced us that the standard "neural correlates of conditioning" approach to sensory systems was futile.

\section{Why study the auditory cortex during classical conditioning?}

At this point, it may have occurred to some readers to ask why the auditory cortex would be of interest in classical conditioning. Indeed, a common question from workers in both the fields of learning/memory and sensory physiology is "Do lesions of A1 impair or prevent classical conditioning?" The answer is generally "No". It has long been known that simple (i.e., single-tone, nondiscriminative) classical conditioned responses can develop after ablation of A1 alone or as part of extensive cortical destruction (e.g., DiCara et al. 1970; Norman et al. 1977; Berntson et al. 1983; Teich et al. 1988; Romanski and LeDoux 1992).

However, this question seems to involve implicit assumptions such that a negative answer, as given above, leads to the

\section{Learning \& Memory \\ www.learnmem.org}


conclusion that A1 cannot be of much interest. These assumptions include: (1) neurophysiological studies of conditioning seek stimulus-response circuitry; (2) the memory trace formed is localized; (3) neurophysiological plasticity that develops is the substrate of the CR; (4) destruction of the site of such plasticity should disrupt the CR.

While all of these assumptions may be relevant to investigation of a single, specific CR (e.g., Christian and Thompson 2005), they do not apply to all neurophysiological studies of conditioning (see Ohl and Scheich 2004 vs. Weinberger 2004b). First, even simple classical conditioning transcends stimulusresponse associations. Rather, conditioning involves many associations, including stimulus-stimulus (CS-US), stimulusoutcome, stimulus-context, etc. Second, neurophysiological studies can therefore be applied to associations other than CS-CR associations. Third, CS-US associations are known to develop rapidly (e.g., in a few trials), preceding CS-CR associations, and therefore may be involved in the development of CS-CR links (e.g., Schlosberg 1937; Mowrer 1947; Konorski 1967; Lennartz and Weinberger 1992a). Fourth, multiple behavioral CRs develop during rapid CS-US learning, e.g., changes in heart rate, respiration, blood pressure, pupillary diameter, skin resistance, behavioral freezing, etc., any one of which can be used to verify that a CS-US association has developed (of course, given appropriate nonassociative controls). Fifth, the total memory for a given event is distributed, although its components may be localized, as in the case of a specific, somatic CS-CR association (e.g., toneeyeblink). Some of the associations are likely to include the relevant sensory systems. After all, auditory memories are not likely to be stored exclusively outside of the auditory system. Other components are likely to involve somewhat specialized systems, such as those processing nociception in the case of a shock US, emotional-processing networks, etc. Sixth, circuitry for a simple CS-CR association can be completely subcortical, so that it survives cortical lesions. However, cortical areas also can store CSUS (and other) information in parallel with subcortical systems. Seventh, cortically stored information could affect immediate behaviors by control over subcortical circuits. Most important, memory traces in the cortex have access to a much greater range of information than sub cortex, and they may store information for the indefinite future, where it can be used in a highly flexible manner to subserve adaptive behaviors. For example, while simple auditory conditioning is not destroyed by lesions of $\mathrm{A} 1$, as soon as two-tone discrimination is demanded, A1 is required (Teich et al. 1988). A1 is also obligatory to achieve experimental extinction (Teich et al. 1989).

Thus, in response to the question posed at the outset of this section, A1 (and other primary sensory cortices) can be profitably studied to determine the cortical "fate" of stimuli that enter into associations. In short, such studies of neurophysiological plasticity can be directed to issues of the representation of stimuli and the transformations that they may develop during learning, without any reference to particular behaviors that index the establishment of stimulus-stimulus associations.

\section{Associative representational plasticity}

Sensory physiology and the neurobiology of learning and memory are the two fields within neuroscience that are concerned with the "fate" of sensory stimuli. The former includes a search for the principles of neural coding, the issue of how the brain represents the world. The latter includes a concern with the transformation of a "neutral" stimulus into a "signal" stimulus that gains new behavioral potential as it enters into associations. This involves another aspect of "representation," viz., the mechanisms by which one stimulus gains some of the properties of other stimuli or events. Although these two disciplines have de- veloped along separate paths, they can be seen as complementary.

Figure 1 points out that sensory stimuli have both physical and psychological parameters. The former are assessed by appropriate engineering devices that can measure, e.g., acoustic frequency (in $\mathrm{kHz}$ ) and level (in $\mathrm{dB} \mathrm{SPL}$ ). The latter are assessed behaviorally, there being no universal behavioral units comparable to $\mathrm{kHz}, \mathrm{dB}$, and the like. Sensory physiology varies the physical parameters and traditionally holds the psychological parameters constant by the use of general anesthesia in animals, thus preventing (inadvertent) learning. In the case of the study of associative processes, the actual sensory stimuli are held constant, but their relationships are varied, e.g., when a CS and US are paired.

A synthesis of the basic approaches of these fields can be accomplished by performing both types of studies in a single experiment. The first step is to perform a sensory neurophysiology experiment by, e.g., determining the receptive field (i.e., acoustic frequency tuning function of A1) before the learning experience. Second, any learning protocol can be run; for the sake of exposition, we assume a tonal CS in simple classical conditioning. The conditioning part of the design need only involve an additional, nonstandard decision: Selection of the CS frequency must be based on knowledge of the "place" of the tonal CS in the receptive field. For example, if the CS is at the peak of the tuning curve (best frequency $[\mathrm{BF}]$ ), then there is danger of a ceiling effect. That is, learning-induced increased response might not be detectable if cells are already firing at their maximum before training. If the CS is selected to be another frequency, then there is the possibility of detecting a tuning shift from the original BF toward or to the CS frequency. Thus, the preferred strategy is to select a non-BF frequency. Third, and finally, step one is repeated, i.e., post-training determination of the frequency tuning function. Short and long-term retention can be studied by obtaining further RFs at desired intervals following training.

Pre- and post-training context should be the same, so that post-tuning changes are attributable to training and are not confounded by a change of context from pre- to post-training periods (e.g., a change in arousal level). The subject's state can be directly monitored (heart rate, EEG) or controlled (e.g., by obtaining pre- and post-training tuning with animals anesthetized). In contrast, training should be in a different context from the determination of receptive fields, to avoid responses to the CS frequency when it is given as one of many frequencies in the post-period, and hence, could produce experimental extinction. Contexts can differ in many ways; they can be different acousti-

\begin{tabular}{|c|c|c|}
\hline \multirow{2}{*}{ Discipline } & \multicolumn{2}{|c|}{ Stimulus Parameters } \\
\cline { 2 - 3 } & Physical $^{\text {a }}$ & Psychological $^{\text {b }}$ \\
\hline $\begin{array}{c}\text { Sensory } \\
\text { Physiology }\end{array}$ & Vary & Constant \\
\hline Learning & Constant & Vary \\
\hline
\end{tabular}

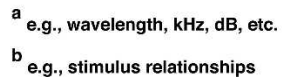

Figure 1. The fundamental paradigms of the disciplines of sensory neurophysiology and the experimental psychology of learning/memory may be viewed as complementary. This entails recognition that stimulus parameters have two basic properties: physical and psychological. Each discipline usually manipulates one of these while holding the other constant. 
cally (e.g., different durations of tone pulses, rates of tone presentation, and actual tonal frequencies presented), visually (e.g., ambient illumination, light vs. dark), and spatially (e.g., different experimental rooms and chambers). We routinely change auditory, visual, and spatial contexts between training sessions and pre- and post-training determination of receptive fields.

This unified design yields the usual behavioral and neurophysiological data for the conditioning phase, i.e., the development of conditioned responses and the development of neural plasticity. But, importantly, it also reveals the effects of associative processes on the detailed processing of conditioned and many other stimuli, plasticity of sensory receptive fields (RFs). Thereby, both fields benefit. For example, sensory physiology can learn the extent to which the encoding of stimuli is affected by experience. The neurobiology of learning/memory can learn the functional significance of associatively induced plasticity in the sensory system of the CS; that is, it can track changes in the representation of a CS as it gains "associative power."

Traditionally, a neurophysiological study of classical conditioning can, and must, determine the extent to which resultant neuronal changes are due to associative vs. nonassociative processes. However, a second step is possible when a sensory physiology approach is included. If the neural plasticity is associative, one can additionally determine the extent to which the plasticity is specific to the value of the CS vs. general. Standard approaches are limited to measuring neural activity during conditioning trials. As noted previously, such studies generally found that responses to the CS are increased during pairing trials (Fig. 2A). However, increased response to the CS could be due to an increased response to all stimuli in the dimension of the CS, e.g., tone frequency if the CS were auditory, angle of orientation if the CS were a visual line segment, or locus of touch on the body surface if the CS were somatosensory. Receptive field analysis, using many stimuli along a dimension within a modality, would show increased responses across the dimension in question (Fig. $2 \mathrm{~B})$. This would constitute general associative plasticity. On the other hand, increased responses to the CS could be due to an effect that was specific to the CS value. In this case, RF analysis would reveal maximal facilitation at the CS value with some combination of smaller increases, no changes, or decreases at other stimuli along the dimension. In toto, the result could be a shift of tuning to the value of the CS (Fig. 2C). This would constitute CS-specific associative plasticity.

The importance of determining the degree of specificity of associative representational plasticity (ARP) is considerable. Four avenues of research will be mentioned here.

First, a major advantage of receptive field analysis is that it provides for the study of specificity of neuronal plasticity. That is, sensory/perceptual representations can be investigated directly, and thus, learning-induced changes in representations can be detected. For example, does the neural representation of a CS actually change in coding (not merely in amplitude) when it acquires a given association or set of associations? Given only responses to the CS before, during, and after training, it is impossible to determine the actual types of plastic changes induced by associative processes. RF (or similar) analysis resolves this issue, in much the same way that behavioral stimulus generalization gradients resolve the issue of the specificity of learning.

Second, the nature of a change in representation can provide a means for investigating the relationships between representational plasticity and changes in behavior or behavior potential. If both post-training receptive fields and generalization gradients were obtained within the same subjects, it would be possible to determine the relationship between the specificity of brain and behavior during learning in all sensory systems and at every level of the neuraxis (brainstem, cerebellum, thalamus, cor-

\section{A. Increased Response to CS on Training Trials}

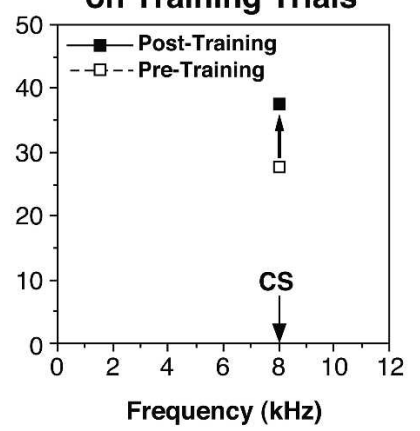

B. General Increase in RF
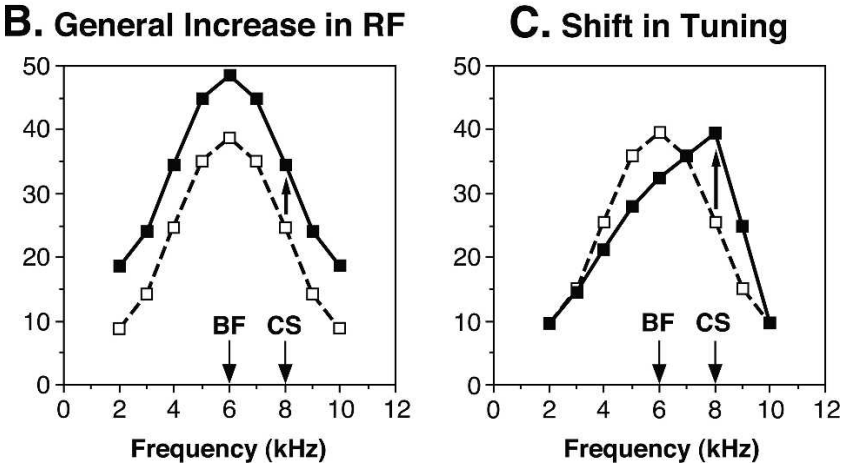

Figure 2. Receptive field analysis reveals whether learning-induced plasticity is general to the dimension of a conditioned stimulus or specific to the value of the CS. $(A)$. During training trials, one can determine whether or not responses to the CS changed; in this case, they increased. However, both general and specific plasticity could produce this result. $(B)$. A general change revealed by receptive field analysis before and after conditioning. (C). A CS-specific instance of associative representational plasticity, in which responses to many non-CS frequencies are reduced, producing a shift in tuning to the frequency of the CS.

tex). Such analyses could be applied to future situations as well as immediate behavior. For example, can the development of an ARP predict subsequent behavior in cases of behaviorally silent learning and in the future when past learning is used to solve a new problem?

Third, research is currently dominated by studies of the processes necessary for the acquisition and maintenance of memory. However, all memories are about something: They have content. The study of ARPs can be used to determine the contents of the neural substrates of memory. Associations are between and among specific elements, be they particular stimuli, responses, outcomes, contexts, or whatever. For example, are ARPs involved only in the acquisition of associations or are they as enduring as behaviorally validated memory? Do ARPs exhibit actual consolidation after initial acquisition, become stronger over time, and less resistant to disruption? Do the forms of ARPs encode the details of associations and memories of their elements?

Fourth, the study of ARPs can illuminate basic issues of associative processes. For example, does an "occasion setter" necessarily develop representational plasticity in order to catalyze associations between and among other stimuli and events? If so, to what extent are the neural substrates of effective occasion setters fundamentally the same or different from the associated elements?

\section{Receptive field and map plasticity}

The unified "receptive field-conditioning" approach was first used in the mid-1980s, but not in A1. Rather, two nonprimary

\section{$4 \quad$ Learning \& Memory \\ www.learnmem.org}


fields (A2) and ventral ectosylvian (VE) were studied, because it was assumed (wrongly as it turned out) that A1 would be less plastic, based on dominant beliefs in auditory physiology. Cats were trained in fear conditioning and developed associative pupillary dilation conditioned responses. Frequency RFs (tuning functions) obtained before and after conditioning revealed CSspecific plasticity: The maximum changes in response were at the CS frequency. Both CS-specific increases and decreases were found. This ARP was retained unless subjects underwent standard extinction training, in which case, tuning returned toward or to baseline status (Weinberger et al. 1984a; Diamond and Weinberger 1986). Importantly, the sign of plasticity that developed during training trials was not necessarily the same as that which was evident in post-training RFs. This finding indicates that context can affect the expression of associative plasticity and has been attributed to performance factors during actual training trials, such as arousal and motivational factors caused by the presence of the unconditioned stimulus (US) (Diamond and Weinberger 1989). Indeed, in the auditory cortex, even associative processes can induce increased tonic arousal level with increased rates of background (spontaneous), single-unit discharges, or even decreased arousal and decreased background unit discharges at the time that subjects "solve" the CS-US contingency, as indexed by the development of CRs (Diamond and Weinberger 1984a,b).

Although such state effects cannot be eliminated during training, they can be eliminated when pre- and post-training RFs are obtained because, as explained above, RFs can be obtained with subjects in a planned, markedly different context that ameliorates or eliminates generalization of, e.g., arousal effects. Generalization also can be prevented altogether by training subjects in the waking state but obtaining pre- and post-training RFs (or frequency maps) with subjects under deep general anesthesia (Weinberger 2004a).

The discovery of ARPs in A2 and VE was largely ignored. This may have reflected the fact that little was known about these auditory fields, which do not contain the fine-grain tonotopic organization found in A1. Thus, an "anything is possible" belief about $\mathrm{A} 2$ and VE would tend to reduce attention to any findings, no matter how distinctive. Indeed, to the extent that these regions might have been considered auditory "psychic" cortex, learning effects would be expected.

Inquiry was thereafter directed to unit discharges in A1. The first such study involved classical fear conditioning in the adult guinea pig (Bakin and Weinberger 1990). Subjects received a single brief training session of tone paired with shock. The CS frequency was selected to not be the pre-training best frequency, to allow for the detection of possible changes in frequency tuning. Subjects developed conditioned responses to the CS following a period of habituation to the CS presented alone. Figure 3 presents typical behavioral data, which was used only to validate CS-US learning, not for the purpose of CR circuit tracing, as explained previously in the section "Why study the auditory cortex during classical conditioning?".

Immediately after training, neuronal RFs had shifted from the pre-training BF toward or all the way to the CS frequency so that it could become the new best frequency (Fig. 4). Shifts were caused by a simultaneous increase in response to the CS frequency, while responses to the pre-training BF and many other frequencies decreased. These tuning shifts were only toward the CS frequency, so were not due to random variation. "Tracking" tuning for weeks revealed only small random fluctuations in best frequency (Galvan et al. 2001). ARPs could be seen even in complex RFs, such as double-peaked tuning (Fig. 5A). Also, responses to the CS frequency alone could develop even when a cell appeared to be nonresponsive to tones (Fig. 5B).

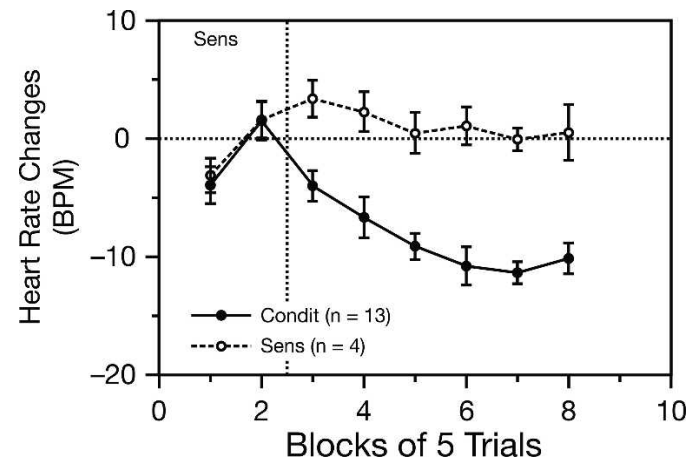

Figure 3. Behavioral verification of associative learning in classical conditioning. Cardiac activity (changes in heart rate to a tone) are shown for two groups of guinea pigs. First, both groups received a tone unpaired with shock for 10 trials (Sens), which resulted in an initial decrease in heart rate during the first block of five trials; this response was no longer present during the second block, perhaps indicating habituation to the tone. Subsequently, one group (Condit) received tone paired with shock, while the other (Sens) continued to receive tone and shock unpaired. Conditioning produced cardiac deceleration CRs as soon as the first block of pairing, which continued to develop across trials. In contrast, the sensitization group showed no such growth of the CR. Such behavioral findings were used to validate the development of a CS-US association, not for purposes of determining CS-CR circuitry (see text).

Subsequent studies revealed that ARP can develop very rapidly (within five trials), is discriminative (increased responses to the $\mathrm{CS}^{+}$, decreased responses to the $\mathrm{CS}^{-}$tone), exhibits consolidation (post-training increased strength over hours and days without further training) (Fig. 6), and could last indefinitely (tracked to 8 wk post-training) (Weinberger 1998). It also developed in avoidance learning (Bakin et al. 1996). Tuning shifts are generally assessed at stimulus levels used for training, i.e., well above threshold (e.g., $70 \mathrm{~dB}$ SPL), although even when trained at one level, they can develop across the range of stimulus levels (10-80 dB SPL) (Galvan and Weinberger 2002). Tuning shifts to the CS frequency are not limited to aversive situations, as they have been found with rewarding brain stimulation as the US (Kisley and Gerstein 2001).

ARPs are highly specific, consistently exhibiting increased responses only at or near the CS frequency across subjects, with decreased responses to lower and higher frequencies (Fig. 7A). CS-specific increased responses and tuning shifts are associative, as they require pairing. Random or unpaired presentation of tone and shock produce increased responses across the frequency spectrum. In fact, general increased responses develop in A1 whether sensitization training involves a tone with random shock or a flashing light with random shock, demonstrating that general increased responses across the frequency RF are truly arousal dependent, not due to auditory processing per se (Fig. 7B) (Bakin et al. 1992). Habituation produces the opposite effect, i.e., a specific decrease in response to the repeated stimulus, with little or no change in response to other frequencies (Condon and Weinberger 1991) (Fig. 7C).

It might be thought that arousal confounds during posttraining testing are responsible for the specificity of increased responses to the CS frequency. That might occur if presentation of this frequency, alone among many other frequencies, produced arousal due to prior conditioning. However, the acoustic context is very different. Pairing involves presentation of random and infrequent presentations of a CS (and US) (mean intertrial intervals not less than $40 \mathrm{sec}$ ), whereas RF determination consisted of the presentation of many frequencies (typically at least 15 ), at many levels (typically $10-80 \mathrm{~dB}$ ) at constant, brief inter- 


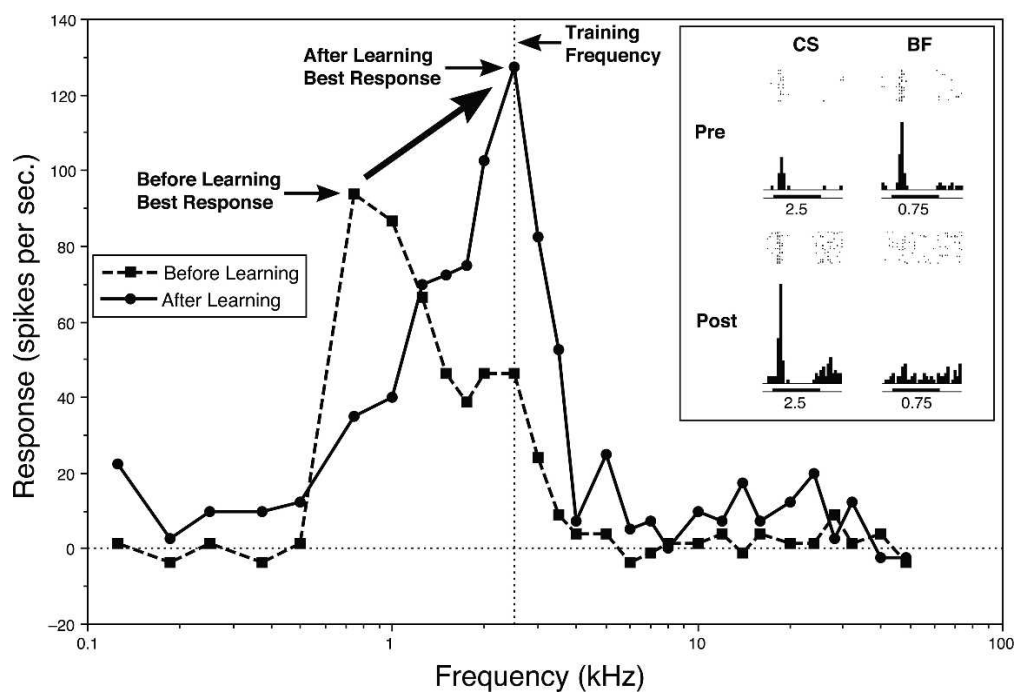

Figure 4. Classical conditioning produces tuning shifts. An example of a complete shift of frequency tuning of a single cell in A1 of the guinea pig from a pre-training best frequency (BF) of $0.75 \mathrm{kHz}$ to the CS frequency of $2.5 \mathrm{kHz}$ after 30 trials of tone-shock pairing, during which the guinea pig developed a cardiac conditioned response. Inset shows pre- and post-training poststimulus time histograms (PSTHs) for the pre-training BF and the CS frequencies.

vals (typically $1-2 / \mathrm{sec}$ ). Direct measurement of the CR behavior revealed no response to the CS frequency when embedded in the post-training stimulus set (e.g., Diamond and Weinberger 1989). Also, the latency of neuronal response to any tone is on the order of 10-50 msec, whereas the latency to detectable EEG activation is well over $100 \mathrm{msec}$ (Weinberger and Lindsley 1964). Moreover, if the CS caused arousal, then the tone following the CS within a few seconds should also show an effect, which was not the case. Finally, ARPs are found when post-training RFs are determined with subjects under general anesthesia (Lennartz and Weinberger 1992b; Weinberger et al. 1993; Rutkowski et al. 2003).

Associative processes were predicted to increase the area of representation of the A1 octave band containing the CS frequency, because the tonotopic map is comprised of preferred frequencies across cortical space, and tuning shifts should increase the number of loci at which the CS frequency is preferred
(Weinberger et al. 1990a,b). This has been demonstrated in a study of the relationship between the level of CS-tonal importance and representational area. Rats were trained to associate a $6.0 \mathrm{kHz}$ tone with the opportunity to bar press for water. The behavioral importance of this CS for different animals was controlled by varying motivational levels by differential amounts of supplemental water, so that asymptotic performance ranged across subjects from $60 \%$ to more than $90 \%$ correct. (As maps cannot easily be obtained more than once within subjects, the pre-post training design was modified to obtain posttraining maps in different groups). Controls received the same schedule of tone presentations, but were trained to bar press only in the presence of a visual stimulus. Maps of the ACx showed an expanded representation for the frequency band centered on the CS. Further, the greater the level of behavioral importance, as indexed by the level of correct performance, the larger the percent of area tuned to the CS (Figs. 8, 9). The control group failed to develop a change in tonotopic organization, not differing from naive subjects. The findings indicate that the amount of representational area induced during associative learning might serve as a "memory code" for the level of acquired behavioral significance of sound (Rutkowski and Weinberger 2005).

In summary, the initial line of research that combines auditory physiological determination of frequency tuning with standard conditioning training revealed that associative processes modify the representation of the conditioned stimulus. Specifically, they systematically alter A1 receptive fields such that responses to the CS are facilitated, while responses to other frequencies are generally decreased, enabling tuning shifts toward and to the CS frequency. This CS-specific tuning plasticity has the major characteristics of associative memory and the amount of increased representation of the CS is proportional to its degree of motivational importance.
A

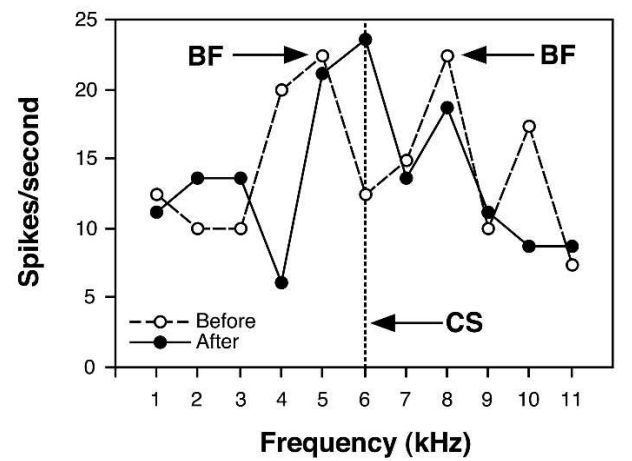

B

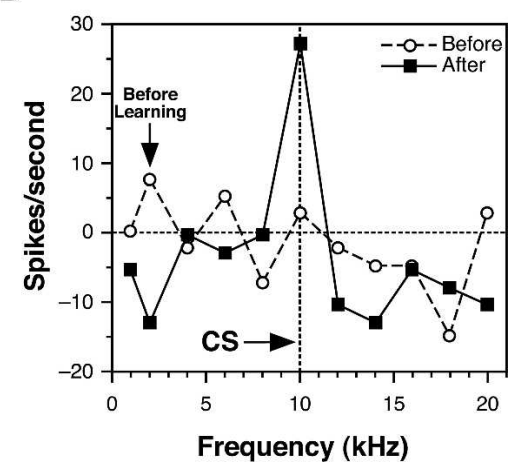

Figure 5. Associative processes favor responses to the frequency of the CS in a variety of circumstances. Single-unit recordings from A1 of the guinea pig. (A) Double-peaked tuning, with pre-training BFs at 5.0 and $8.0 \mathrm{kHz}$. The CS was selected to be $6.0 \mathrm{kHz}$, a low point. After conditioning (30 trials), responses to the CS frequency increased to become the peak of tuning. $(B)$. A cell that exhibited minimal or no response to tones before tuning developed tuning specifically to the CS frequency after conditioning (30 trials).

\section{Learning \& Memory}

www.learnmem.org

\section{Controversies: The importance of behavioral factors}

Following the development of this line of inquiry, several major controversies arose. These include opposing claims regarding the form of receptive field plasticity, the interpretation of its functional significance, and its underlying neural mechanisms. The position taken here is that these controversies reflect "growing pains" in the field, due to failures to appropriately combine approaches from the disciplines of learning/memory with those of auditory neurophysiology. More specifically, I will suggest that the underlying problem is a failure to understand the critical importance of behavioral factors, including insufficient appreciation of the need to actually obtain behavioral evidence of learning, inadequate 
A. Pre

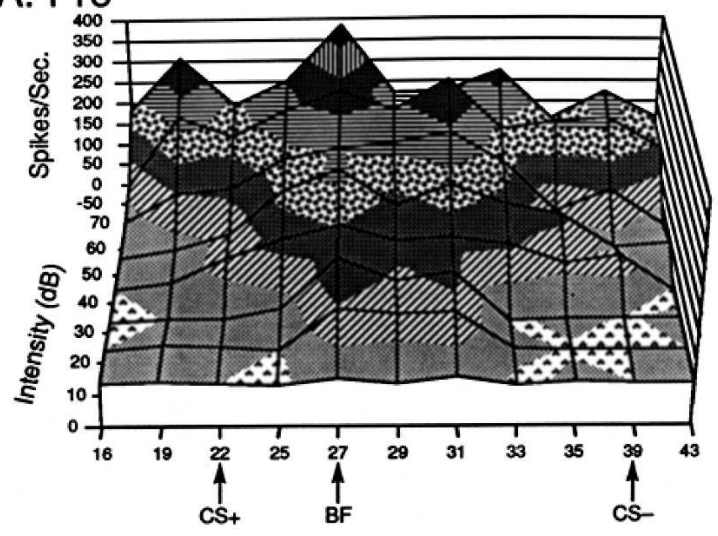

C. One Hour Post

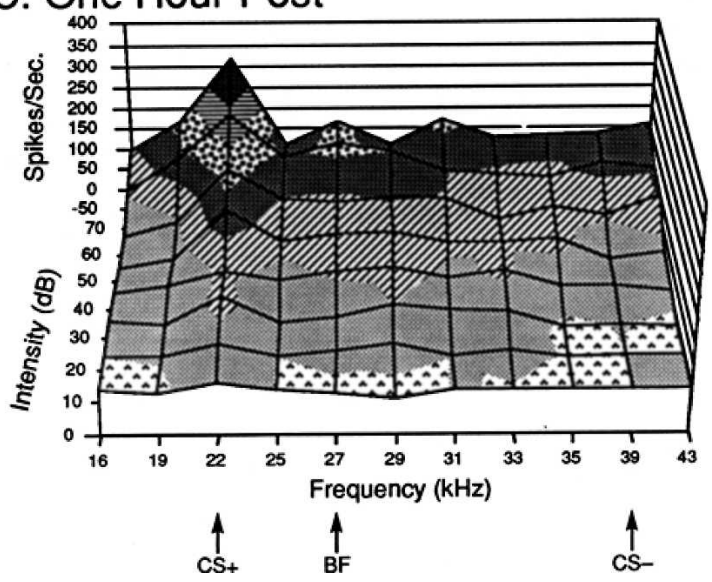

B. Post

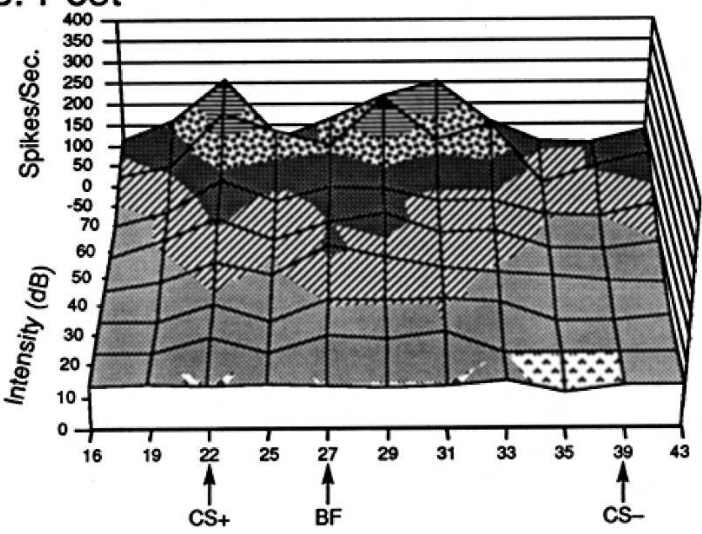

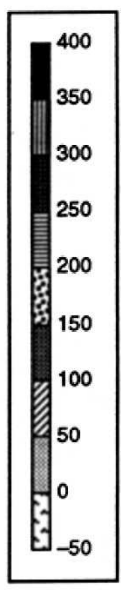

Figure 6. Representation of neuronal responses in $\mathrm{A} 1(A)$ before, $(B)$ immediately after, and $(C) 1 \mathrm{~h}$ after two-tone discrimination training. The guinea pig received 30 each $\mathrm{CS}^{+}(22.0 \mathrm{kHz})$ and $\mathrm{CS}^{-}(39 \mathrm{kHz})$ intermixed trials. Displayed are rates of discharge $(y$-axis) as a function of tonal frequency $(x$-axis) and level of testing stimuli $(y$-axis, 10-70 dB). Note that conditioning changed the "topography" of neuronal response. The pre-training best frequency of $27.0 \mathrm{kHz}$ suffered a reduction in response as did the $\mathrm{CS}^{-}$frequency. In contrast, responses to the $\mathrm{CS}^{+}$frequency increased. Strikingly, consolidation, in the form of a continued development of these changes is evident. After a period of $1 \mathrm{~h}$ of silence, the only excitatory response is at the CS ${ }^{+}$frequency.

experimental designs, and lack of knowledge of the relevant behavioral literature.

\section{The form of associative receptive field plasticity}

Ohl and Scheich $(1996,1997)$ have claimed that associative learning in the gerbil induces decreased responses at the CS frequency, i.e., the opposite direction of change found previously.
They propose that this provides for "contrast enhancement," not increased stimulus importance. However, their data were obtained from a behavioral paradigm that has two shortcomings. First, they used a classical aversive discrimination protocol in which a single $\mathrm{CS}^{+}$(paired with shock) was intermixed with 1130 different $\mathrm{CS}^{-}$(no shock) frequencies in a single training session. However, there is no prior evidence that animals can learn

\section{A. Conditioning}

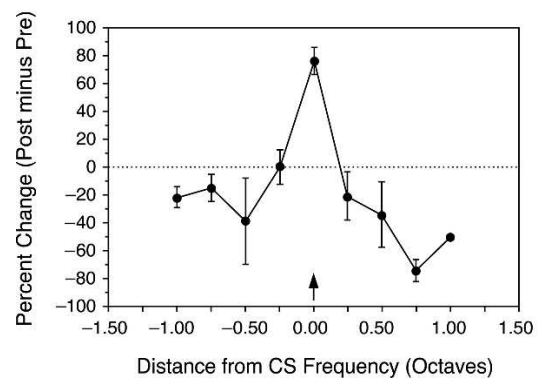

B. Sensitization

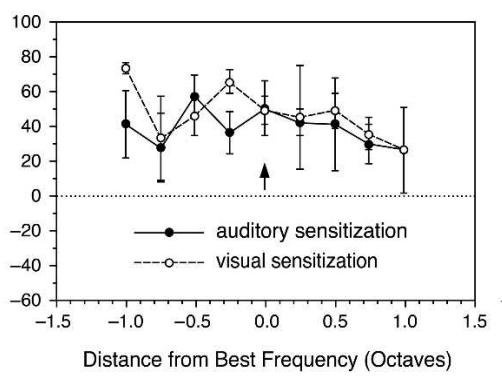

C. Habituation

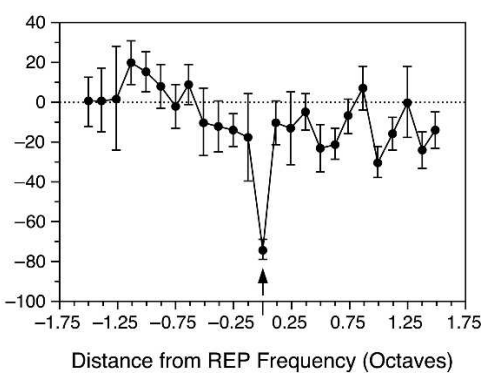

Figure 7. Summary of the effects of $(A)$ conditioning, $(B)$ sensitization, and $(C)$ habituation on frequency receptive fields in the primary auditory cortex of the guinea pig. Data are normalized to octave distance from the CS frequency $(A)$, the presensitization best frequency $(B)$ or the repeated frequency (C). Note that conditioning produces a CS-specific increased response, whereas sensitization (tone-shock or light-shock unpaired) produces general increases across the spectrum. Habituation produces frequency-specific decreased response. 


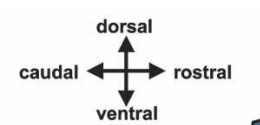

Naïve
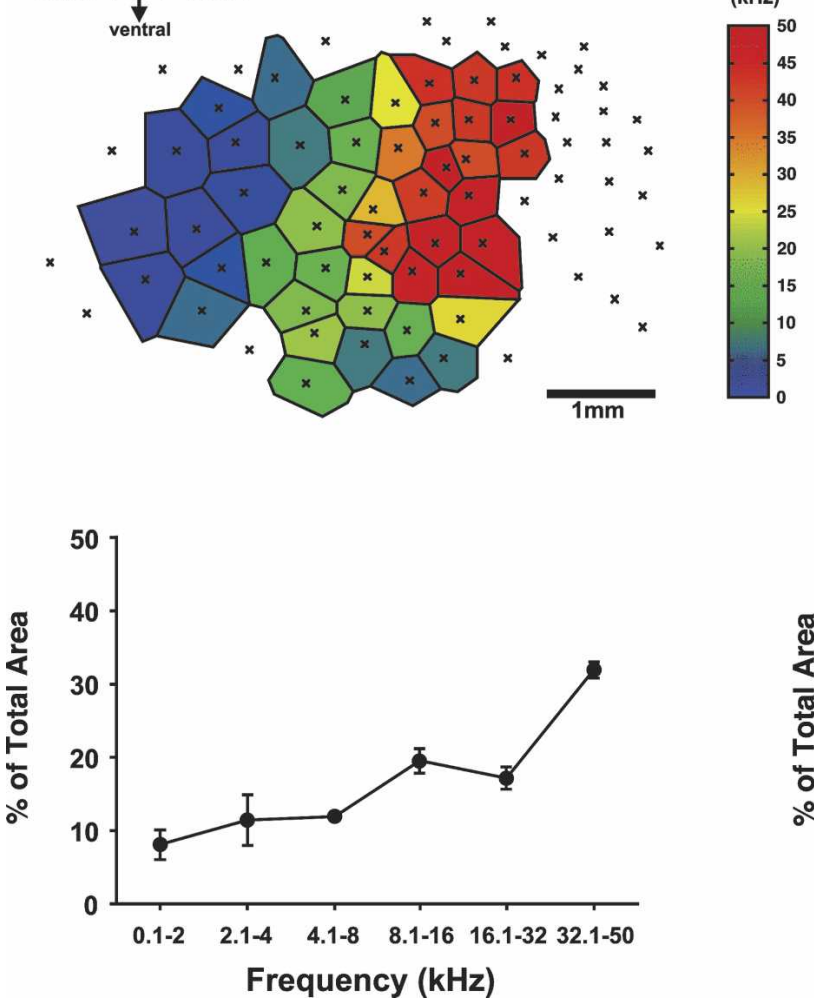

K3 $(90 \%)$ $\mathrm{CS}=6.0 \mathrm{kHz}$
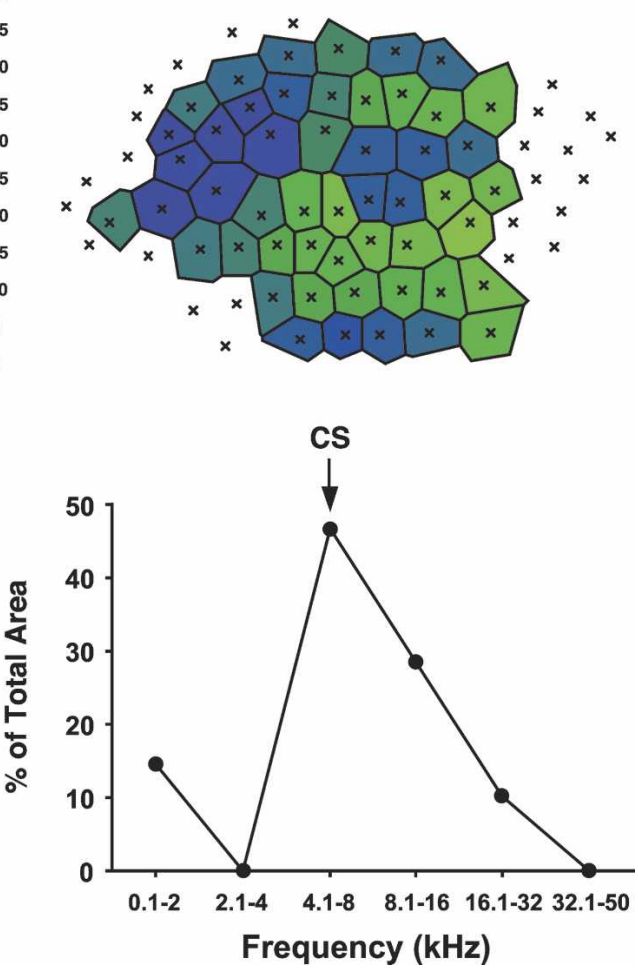

Figure 8. Effect of learning tone-contingent bar-press for water on tonotopic map in A1. Trained rats received water reward for bar-presses in the presence of a $6.0 \mathrm{kHz}$ tone. Illustrations show tonotopic maps and quantifications of percent of total area (octave frequency bands) for a naïve rat (left) and a rat that attained over $90 \%$ correct performance (right). Note that training greatly increased the area of representation for the frequency band containing the $6.0 \mathrm{kHz}$ tone signal.

this highly complex discrimination, particularly in a single session. The investigators provided no behavioral evidence that their subjects had learned the discrimination. Heart rate was recorded but not related to any particular $\mathrm{CS}^{+}$or $\mathrm{CS}^{-}$stimuli. Indeed, such data may not have been attainable because they used extreme massing of intertrial intervals, which varied from 0.25 to $3 \mathrm{sec}$. Second, they compared RFs obtained in a pre-training state of quiet with those from a different post-training state, one involving expectation of shock and possibly new learning. The

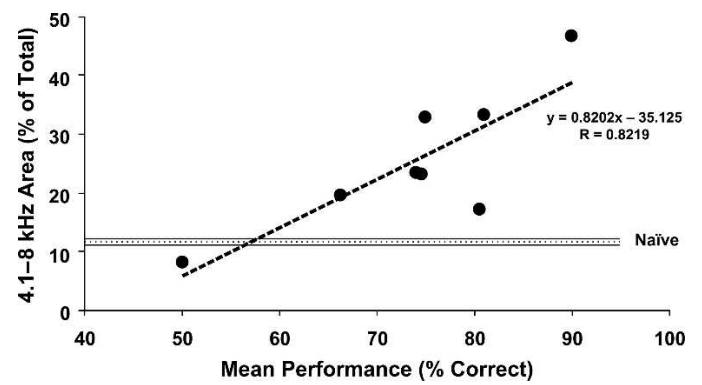

Figure 9. Evidence of a "memory code" for the acquired behavioral importance of sound. Level of tone importance was controlled by the amount of water deprivation; asymptotic performance was significantly correlated with level of deprivation (for details, see Rutkowski and Weinberger 2005). The area of representation of the frequency band containing the $6.0 \mathrm{kHz}$ tone signal increases as a direct function of the level of behavioral importance of the tone, as operationally indexed by the level of correct performance. post-training state must have been different from pre-training, because Ohl and Scheich used a design in which the same acoustic context (i.e., the identical tone stimulus set) was presented before, during, and after tone-shock pairings. As shock was paired with a $\mathrm{CS}^{+}$that was intermixed with numerous other tones, presentation of the same stimuli after pairing probably involved an expectation of shock, at least until subjects may have learned that shock had been deleted. The latter would constitute some sort of extinction, i.e., new learning. That the pre- and post-training periods differed in expectation, probable state of arousal, or in other ways, precludes attributing post-training changes in neural responses to (alleged) discrimination learning.

$\mathrm{Ohl}$ and Scheich not only argue that conditioning produces CS-specific decreased responses, but that prior observations of decreased responses have been ignored by this investigator in order to promote our claim of increased responses to the CS (Ohl and Scheich 1996, 1997, 2004, 2005). They are correct that decreased unit responses to the CS can be found (e.g., Diamond and Weinberger 1984b, Weinberger et al. 1984b), but these findings are irrelevant to the issue of associative representational plasticity, as they occurred during training trials. Ohl and Scheich make no distinction between plasticity that is observed during training trials from that which is observed after training trials. But, a central point of the unified design presented in this article is that it reduces or eliminates performance factors, such as state changes, that must occur during training trials when a reinforcer is introduced. It does so by use of pre- and post-training RF determinations and in a context different from the context of training trials. It is well known that performance factors severely limit

\section{Learning \& Memory}

www.learnmem.org 
the interpretation of behavioral data obtained during training trials, as opposed to after training trials (Rescorla 1988a,b). The same strictures are no less important for determining the neural correlates of associative processes during training trials. A striking example of the Ohl and Scheich fallacy is that the sign of plasticity (increase or decrease in response to the CS) is often different during training from after training, as noted above (Diamond and Weinberger 1989).

The failure of Ohl and Scheich to appreciate the essential requirement that behavioral validation of learning is necessary to support a claim that learning has occurred does not invalidate the possibility of learning-induced decreased responses to the CS. There well may be circumstances under which such decreases do develop. But neither should the lack of behavioral evidence be ignored, as the investigators continue to do (Ohl and Scheich 2005). At this time, CS-specific increases, CS-directed tuning shifts, and CS-expansions of area in the tonotopic map remain the only behaviorally validated ARPs in the primary auditory cortex. The Ohl and Scheich findings of CS-specific decreases in A1 do not challenge this conclusion because of the absence of behavioral verification of associative learning. If this is forthcoming, then the domain of associative representational plasticity in the primary auditory cortex will have been enlarged, and a next step would be to discover the superordinate rules that govern which types of ARPs are invoked by associative processes and their respective functional consequences.

\section{Consequences of failure to understand fundamental aspects of conditioning}

Interestingly, studies in the big brown bat (Eptesicus fuscus) have reported CS-specific tuning shifts during tone-shock pairing (Suga and Ma 2003). However, they also lack behavioral validation of association, although, in this case, behavioral data were said to have been obtained. The investigators presented sessions of 60 trials of tone-shock pairing and reported that limb flexionconditioned responses developed starting at trial 50 (Gao and Suga 1998). However, there is reason to suspect the claims of behavioral learning. First, these investigators have consistently failed to publish individual flexion records, learning functions, or any statistical report of the behavioral data. Second, their previous study showed a failure of acquisition of flexion CRs with tone CSs and required many days of training to obtain consistent CRs using an effective white noise CS (Riquimaroux et al. 1992). Third, the animals are under whole body restraint while being trained with shock, and access to the brain is obtained by drilling a hole in the skull while they are awake. These procedures are likely to cause considerable stress and might increase limb movement during a session. Konorski (1967) has emphasized the problem of generalized body movement in such circumstances, which can produce apparent flexion CRs. Fourth, intertrial intervals were fixed at $30 \mathrm{sec}$. Therefore, any genuine CRs could have been caused by temporal conditioning, without any control by the tonal CS itself. Fifth, the investigators treated extinction as "erasure," assuming that repeated training of subjects after extinction was equivalent to training naive subjects. Only data from the first session would be clearly interpretable, but data from all sessions and subjects were combined. There are also neurobiological reasons for caution. Suga and coworkers have relied on findings from cortical inactivations using muscimol. Interpretation of the claimed highly focal effects of this drug depend upon assurances that its diffusion was limited to $\sim 1 \mathrm{~mm}$, due to the proximity of primary somatosensory and auditory cortices. However, radiotracing studies of muscimol diffusion, using smaller doses than used in these studies, has revealed a considerably more extensive spread (Edeline et al. 2002). Finally, Suga and colleagues found that repeated presentation of a tone alone produced increased response to and tuning shifts toward the repeated frequency (Gao and Suga 1998). This is in direct opposition to the extensive literature on the effects of repeated auditory stimulation, which produces response decrements (habituation) in the auditory cortices in other taxa (e.g., Marsh and Worden 1964; Ellinwood et al. 1968; Wickelgren 1968; Weber 1970; Oleson et al. 1975; Weinberger et al. 1975; Westenberg and Weinberger 1976; Condon and Weinberger 1991).

Thus, despite the temptation to assume that associative tuning shifts develop in the big brown bat during the development of conditioned responses, the claims of Suga and colleagues must remain suspect in the absence of appropriate behavioral and neural controls. Perhaps as an echolocating animal, the principles of auditory system plasticity are specialized in the big brown bat, and thus, it is not a good model for general mammalian auditory associative plasticity.

\section{Mechanisms and models of ARP and associative memory}

I conclude with a consideration of mechanisms that may be responsible for the development of associative representational plasticity, focusing on the cholinergic system because it has garnered most attention. There is little controversy about the importance of acetylcholine (ACh) in auditory cortical (and other cortical) plasticity. The same cannot be said for the two extant models of ARP, which are in direct conflict on all issues except the role of acetylcholine.

\section{The nucleus basalis, acetylcholine, and associative representational plasticity}

Neuromodulators have profound effects on neuronal functions. With respect to the auditory cortex, norepinephrine can alter frequency tuning (Manunta and Edeline 1997, 1999), dopamine can increase the area of cortical representation of a tone with which it is paired (Bao et al. 2001), and serotonin levels can increase during initial stages of avoidance training (Stark and Scheich 1997). Acetylcholine has long been implicated in associative learning, (e.g., Deutsch 1971; Introini-Collison and McGaugh 1988) and also the auditory cortex. For example, ACh, and stimulation of the nucleus basalis (NB), its cortical source (Mesulam et al. 1983), can modulate the responses of A1 to sounds (Ashe et al. 1989; McKenna et al. 1989; Metherate et al. 1990; Metherate and Ashe 1993), regulate intracortical processing (Hsieh et al. 2000), synaptic plasticity (Metherate and Ashe 1995; Aramakis et al. 1997, 1999; Bandrowski et al. 2001), and learning-induced auditory cortical plasticity in animals (Metherate and Weinberger 1989; Shulz et al. 1997; Kudoh et al. 2004; Ma and Suga 2005) and humans (Thiel et al. 2002a,b); see also (Edeline 2003; Weinberger 2003; Metherate et al. 2005).

While the direct application of cholinergic agonists and antagonists to the brain (both in vitro or in vivo) has provided important insights into the roles of ACh in the auditory system, plasticity, and learning, this approach is necessarily limiting with respect to associative processes in behaving subjects. A major obstacle is the difficulty of achieving precise timing when it is desirable to use a cholinergic agent as a US following presentation of an acoustic CS because of the uncontrolled time lag in diffusion of drugs applied to the brain. Electrical stimulation of the NB does permit precise timing and such stimulation is known to release ACh in the cortex (Rasmusson et al. 1994; Detari et al. 1997a; Duque et al. 2000). Moreover, NB stimulation appears to be motivationally neutral (Pennartz 1995; Miasnikov et al. 2004), thus avoiding potential confounds due to reward or punishment.

In the first study of this type, a tone was paired with $\mathrm{NB}$ stimulation as a substitute for the US in one group of waking 
guinea pigs or presented unpaired in another group. Frequencytuning curves were obtained before and after a single training session of only 40 trials (Bakin et al. 1996). Pairing induced ARP, i.e., responses to the CS frequency were augmented, while those to the pre-training $\mathrm{BF}$ and many other frequencies decreased. Subsequent similar studies demonstrated that CS-specific tuning plasticity induced by using NB stimulation as the US was specific to a $\mathrm{CS}^{+}$vs. a $\mathrm{CS}^{-}$in two-tone discrimination training (Dimyan and Weinberger 1999) and that it exhibits consolidation over a 24-h period of retention, i.e., the effects become larger in the absence of further training (Bjordahl et al. 1998). The cholinergic nature of associative NB-induced CS-specific tuning plasticity is evidenced by the fact that it requires NB induction of EEG activation (Bjordahl et al. 1998), which is known to involve the release of ACh in the cortex (Metherate et al. 1992; Detari et al. 1997b; Cape and Jones 2000; Duque et al. 2000) and the engagement of muscarinic receptors in A1 (Miasnikov et al. 2001). In summary, ARPs induced by nucleus basalis/cholinergic activation have the same characteristics as ARPs that develop during associative learning.

A series of related studies replicated and extended CSspecific frequency tuning plasticity (Kilgard and Merzenich 1998a) and also demonstrated that pairing NB stimulation with other acoustic stimuli, e.g., frequency-modulated sweeps, sounds presented at particular pulse rates, and sequences of different acoustic stimuli (tones and noise) was sufficient to produce CSspecific facilitation (Kilgard and Merzenich 1998b, 2002; Kilgard et al. 2001; Moucha et al. 2005; Pandya et al. 2005). However, all of these experiments presented hundreds of trials per day for periods of weeks, thus involving from about 6000 to 12,500 trials. Further, some studies lack controls for nonassociative processes (Kilgard and Merzenich 1998a,b). This training approach contrasts with the studies summarized above that mimic standard behavioral conditioning protocols, e.g., 40 trials for singletone conditioning and 30 trials each of a $\mathrm{CS}^{+}$and $\mathrm{CS}^{-}$for discrimination training, all in a single session (Bakin and Weinberger 1996; Bjordahl et al. 1998; Dimyan and Weinberger 1999). Therefore, the extent to which massed pairing of tone and NB stimulation sheds light on basic associative processes is unclear.

\section{Induction of specific, associative behavioral memory by stimulation of the NB}

Recent experiments indicate that pairing a tone with NB stimulation induces not only ARPs in A1, but also CS-specific behavioral memory. Inferences that such pairing produces specific, associative memory have to meet the dual criteria of associativity and specificity. The first criterion simply requires a nonpaired control group. The criterion of specificity can be examined by obtaining stimulus generalization gradients, obtained when a subject is trained with one stimulus (CS) and later tested with many stimuli. If NB stimulation paired with a tone induces specific memory about that tone, then this CS frequency should later elicit the largest behavioral responses to all tones tested, i.e., occupy the peak of the frequency generalization gradient.

The first study involved overtraining using 200 daily trials for $15 \mathrm{~d}$ (3000 trials). This is the same order of magnitude used by Merzenich and colleagues in studies of the induction of neuronal plasticity by stimulation of the NB (above). However, the induction of specific associative behavioral memory by NB stimulation had never been demonstrated, and we assumed (wrongly as it turned out) that as NB stimulation was motivationally neutral, overtraining might be necessary to induce behavioral memory. The behavioral measures were changes in heart rate and in respiration. This protocol did produce CS-specific memory (McLin
III et al. 2002); generalization gradients for the paired group exhibited peak response at the CS frequency, in contrast to the control group (Fig. 10). This appears to be the first description of the induction of specific associative memory by direct stimulation of the brain. Overtraining proved unnecessary; a single session of 200 trials has proven to be sufficient (Miasnikov et al. 2006). The minimal amount of training has not yet been determined. The frequency generalization gradients are indistinguishable from those that develop in standard learning protocols using standard motivational reinforcers (Mackintosh 1974). Thus, the behavior meets the same criteria as used to assess learning under normal circumstances.

NB stimulation not only can induce specific, associative memory, but actually control the amount of detail in that memory. In a very recent study using a $2 \times 2$ design, rats received tone and $\mathrm{NB}$ stimulation either paired or randomly with either low $(\sim 45 \mu \mathrm{A})$ or moderate $(\sim 65 \mu \mathrm{A})$ levels of NB stimulation. Previous studies of CS-specific memory induction (above) had used the moderate level. As in the past, the moderate paired group developed associative CS-specific memory; the only significant increased response was at the spectral range containing the CS frequency $(6.0 \mathrm{kHz})$. In contrast, the weak stimulation group developed only associative memory without any frequency specificity (Fig. 11). Additional experiments are needed to further characterize the contents or detail in such memories. The current results are consistent with the conclusion that the weak paired group learned that tone (or sound per se) had become important, whereas the moderate paired group had learned

A.

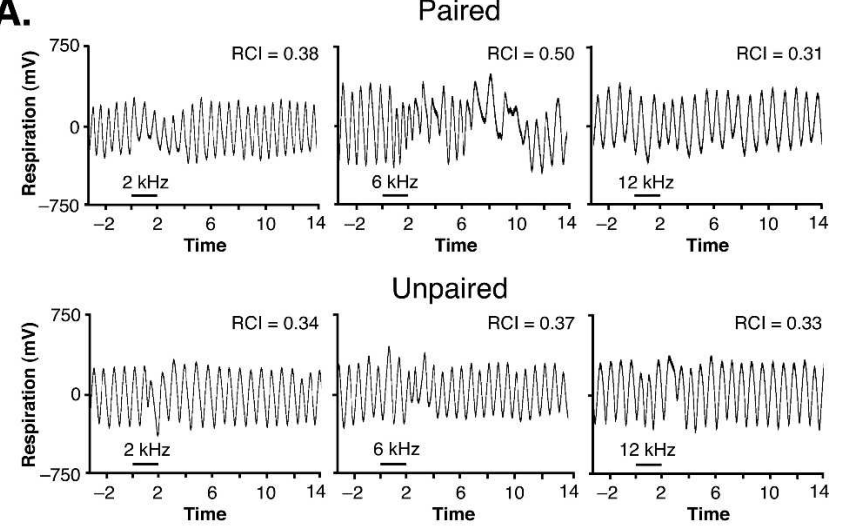

B.
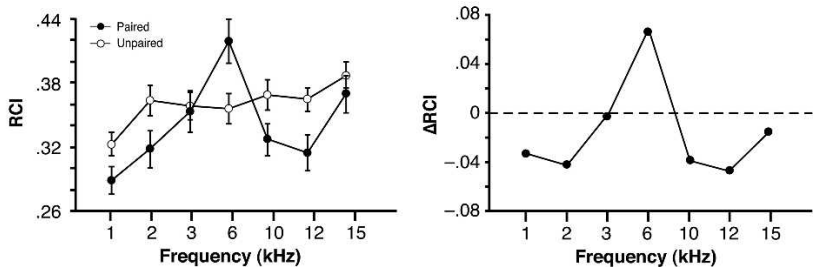

Figure 10. Respiration responses to post-training tone and generalization gradients, showing the induction of CS-specific memory after tone paired with stimulation of the nucleus basalis. $(A)$ Examples of individual respiration records (with value of respiration change index, $\mathrm{RCl}$ ) to three frequencies $(2,6$, and $12 \mathrm{kHz})$ for one animal each from the paired and unpaired groups. The largest response was at the CS frequency of $6 \mathrm{kHz}$ for the paired animal $(\mathrm{RCl}=0.50)$. Horizontal bar indicates tone duration. $(B$, left) Group mean ( \pm SEM) change in respiration to all tones for both groups. The maximal response (left) was at $6 \mathrm{kHz}$ for the paired group, but not for the unpaired group. The generalization gradient for only the paired group was significantly quadratic $(P<0.01)$, with responses to 6 $\mathrm{kHz}$ being of greatest magnitude. The group difference function (right) shows a high degree of specificity of respiratory responses to $6 \mathrm{kHz}$. 
A. Pre-Training

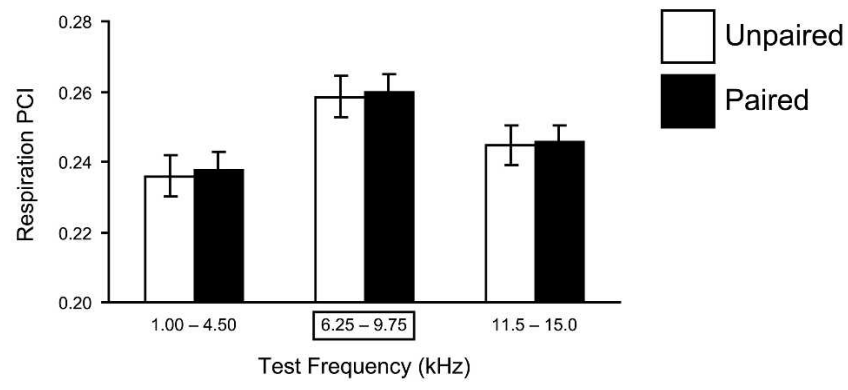

Moderate NBs

\section{B. Post-Training}

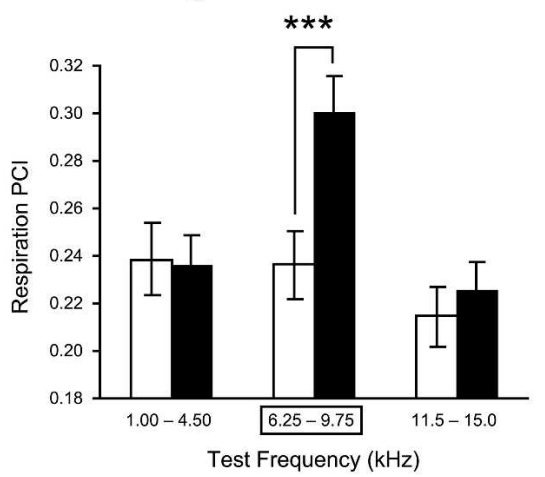

C. Post minus Pre-Training

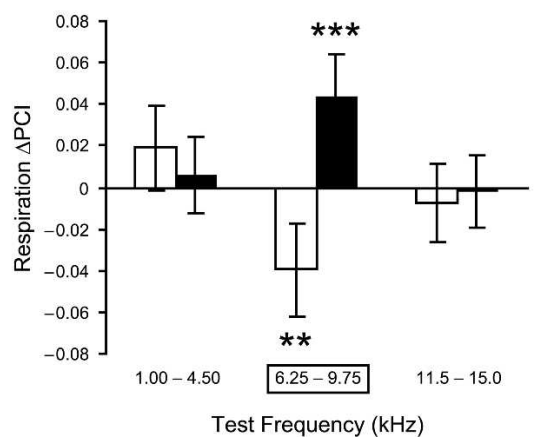

Weak NBs

\section{Post-Training}

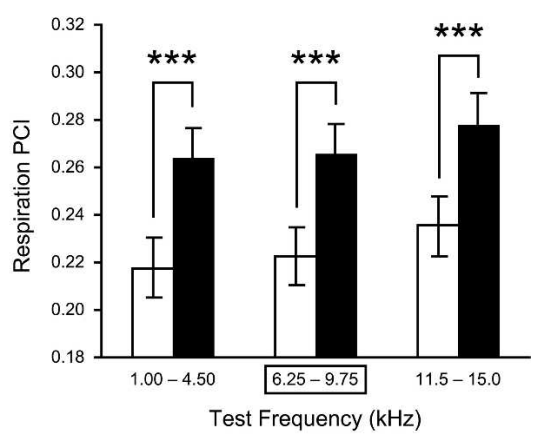

E. Post minus Pre-Training

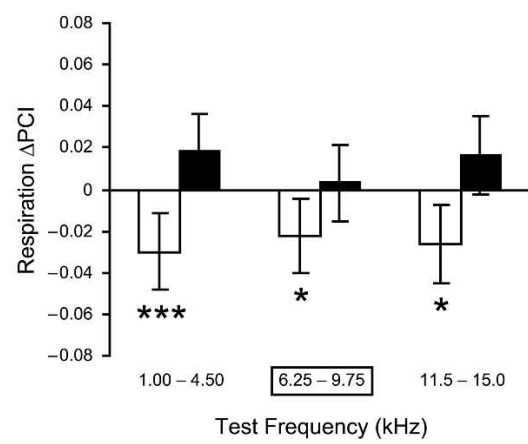

Figure 11. Level of NB stimulation controls specificity of induced memory. Pre-training and posttraining responses to test tones in the Moderate and Weak NB stimulation (NBs) groups. $(A)$ Pretraining responses for subjects later trained with either paired or unpaired CS tone and NB stimulation. There were no differences between the groups. (B) Post-training responses for the Moderate NBs groups. Note the significant difference between the paired and unpaired groups, confined to the CS-band frequencies. This indicates that training with a moderate level of NBs produced memory that was both associative and CS specific. (C) Comparisons of changes within the Moderate group (postminus pre-training responses to test tones). Note that the paired group had developed a significant increase to the CS-band frequencies only, while the unpaired group had developed a significant decrease, probably indicating frequency-specific habituation due to lack of pairing with NB stimulation. (D) Post-training responses for the Weak NBs groups. In contrast to the Moderate NBs group, pairing produced a significant difference in response across all test frequencies compared with its unpaired controls. This indicates that training with weak NBs was sufficient to produce associative memory but insufficient to produce memory for frequency detail, i.e., memory that the frequency of the CS was paired with NBs. (E) Comparisons of changes within the Weak NBs groups showed that the paired group did not develop absolute increased responses, but that the unpaired group did develop significant decreases in responses across the spectrum of test frequencies. Thus, pairing the CS with weak NBs apparently prevented a habituatory decrement in the Weak paired group, which is evident in the Weak unpaired group. ${ }^{*} P<0.05 ;{ }^{* *} P<0.01 ;{ }^{* * *} P<0.005$.

that the CS frequency (and its neighbors) had become important. In the absence of a normal US, neither group would have learned why these stimuli were important (Weinberger et al. 2006).
In summary, these findings support the view that the NB is normally engaged during associative $\mathrm{S}-\mathrm{S}$ conditioning, promoting the establishment of specific cortical plasticity that itself may be a substrate for specific behavioral memory. The use of NB stimulation to induce memory may not only elucidate the mechanisms of memory induction but also allow "dissection" of memory into its components of sensory content and level of behavioral importance. During normal motivated learning, both aspects of memory may be stored when a standard reward or punishment is present and the NB is activated. In the present studies lacking a standard US, behavioral importance can be induced in the absence of a full CS-US association.

Neural models of associative receptive field plasticity and behavior

A preliminary model of CS-specific receptive field plasticity was proposed at the outset of this line of research (Weinberger et al. 1990a,b). Its goal was to outline the minimum circuitry sufficient to account for both the cortical plasticity and behavioral (autonomic) fear conditioning (Fig. 12). The key ideas were (1) CS-US convergence occurs first in the (nonlemniscal) magnocellular medial geniculate nucleus (MGm), where the resultant plasticity results in shifts of tuning that favors the CS frequency; (2) projection of this MGm plasticity to the amygdala; (3) projection of the effects of the plasticity (i.e., increased response to the CS) from the amygdala to both the cholinergic nucleus basalis and to brainstem nuclei controlling autonomic behavioral responses (e.g., heart rate); (4) convergence of MGm and auditory lemniscal tonal information in the primary auditory cortex to promote shortterm plasticity; and (5) convergence of $\mathrm{NB} / \mathrm{ACh}$ and auditory information in $\mathrm{A} 1$ to promote long-term plasticity. This model incorporated many established findings (such as the convergence of auditory and nociceptive somatosensory information in the MGm (Wepsic 1966; Love and Scott 1969), the necessity for an intact MGm region for auditory fear conditioning (LeDoux et al. 1983, 1986a; Jarrell et al. 1986a) and the ability of NB/ cholinergic influences to facilitate cortical responses in sensory cortex (Metherate et al. 1987; Ashe et al. 1989).

This model was soon shown to be incorrect. Thus, while it hypothesized that the lemniscal ventral medial geniculate (MGv) was not plastic and sent only the "physical parameters" of sound to A1, in fact, the MGv develops CS-specific tuning plasticity, although it is transient, disappearing by 1-h post-training (Edeline and Weinberger 


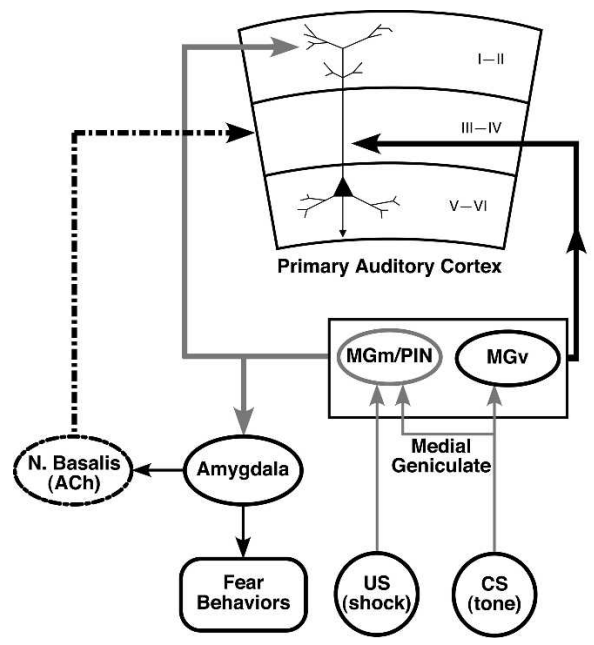

Figure 12. The model of Weinberger and colleagues. This model hypothesizes the minimal circuitry that would be sufficient to account for short- and long-term associative representational plasticity and rapidly acquired conditioned autonomic responses. See text for details.

1991). We have not been able to formulate a reasonable revision of the model that explains both the source of the brief CS-specific plasticity in the MGv and the functional implications of this plasticity. Regarding sources, it is certainly possible that corticogeniculate connections could be responsible, and it is intriguing that cortical stimulation appears to facilitate MGv cells while inhibiting nonlemniscal medial geniculate neurons ( $\mathrm{Yu}$ et al. 2004). But, this in itself would not explain the specificity of CStuning plasticity in the MGv. Thus, even reasonable speculation needs more detailed knowledge of cortico-fugal transactions in the MGv (He 2003). As for the functional implications, the transient plasticity in the MGv could be responsible in part for setting up the enduring plasticity in the cortex. But, as for the model itself, two time scales would have to be reconciled, that of less than an hour in the MGv and that of months in the auditory cortex. Mere postulation of dual temporal mechanisms in the cortex would be little more than an expression of current ignorance. Thus, while several avenues of speculation are possible, rather than construct a tenuous and untestable modification of the model, we await further empirical developments.

However, the model has been successful in several respects. For example, it predicted CS-specific tuning plasticity in the MGm (Edeline and Weinberger 1992), the ability of electrical stimulation of the MGm to substitute for the shock US in fear (cardiac) conditioning (Cruikshank et al. 1992), CS/tone associative plasticity in the NB that precedes associative tuning shifts in A1 (Maho et al. 1995), and the ability of electrical stimulation of the NB to substitute for the US to induce CS-specific tuning plasticity in A1 (Bakin and Weinberger 1996; Kilgard and Merzenich 1998a) that is dependent on muscarinic receptors in A1 (Miasnikov et al. 2001). It also explains why lesions of the MGm block both associative plasticity that develops in the amygdala and elsewhere in the brain, and also impairs conditioning (Poremba and Gabriel 1997). Additionally, imaging studies in humans have obtained results predicted by the model. For example, aversive two-tone discriminative conditioning produces CS-specific plasticity in the primary auditory cortex and associative changes only in the medial geniculate, amygdala, basal forebrain, and orbitofrontal cortex (Morris et al. 1998). These structures, except the orbitofrontal cortex, are the core of the model.

Suga and colleagues have proposed an alternative model
(Suga and Ma 2003). It ignores the MGm completely but rather holds that the CS and US ascend to the auditory and somatosensory cortices, respectively, and are projected to association cortex, which is said to be the locus of CS-US convergence, and then to the amygdala. This model also includes the descending (corticofugal) auditory system and asserts that plasticity that develops in the association cortex is relayed (via the amygdala) to the inferior colliculus, which in turn promotes CS-specific plasticity in A1. Finally, cortico-collicular projections are thought to induce CS-specific response increments in the inferior colliculus, thus forming a cortico-colliculo-cortico positive feedback loop. The investigators suggest that this positive feedback loop is turned off by the thalamic reticular nucleus (TRN), which prevents auditory information from reaching A1. Suga and colleagues do not specify how or when the TRN is engaged. Their formulation also seems to ignore the fact that the auditory cortex of conditioned animals continues to receive perfectly fine auditory information. The Suga model accepts the components of the Weinberger et al. model that (1) link the amygdala to the initiation of behavioral CRs, (2) hypothesize that the amygdala engages the nucleus basalis, and (3) suggests that the cholinergic projections of the nucleus basalis to A1 promote long term CSspecific tuning shifts therein.

Why Suga and colleagues ignore the MGm is baffling. It projects to Layer I and the apical dendrites of pyramidal cells in A1 and in all other auditory cortical fields (Winer and Morest 1983) and does so via giant axons that provide the fastest thalamo-cortical transmission (Huang and Winer 2000). In addition to findings listed above that implicate the MGm (and its related posterior intralaminar nucleus [PIN]) in associative learning, this structure is well known to develop associative plasticity during conditioning (Gabriel et al. 1975, 1976; Disterhoft and Stuart 1976; Birt et al. 1979; Birt and Olds 1981; Weinberger 1982; Jarrell et al. 1986b; LeDoux et al. 1986b; Edeline et al. 1988, 1990; Edeline 1990; McEchron et al. 1995, 1996; Hennevin et al. 1998). Moreover, its stimulation induces in the auditory cortex heterosynaptic (Weinberger et al. 1995) long-term potentiation (LTP), which has been implicated in learning (see also Parsons et al. 2006).

Another inexplicable feature of the Suga model is their claim that CS-US convergence occurs in the cerebral cortex. This is incompatible with an extensive literature which shows that neither the auditory cortex, nor indeed the cerebral cortex as a whole, are necessary for simple classical conditioning (DiCara et al. 1970; Norman et al. 1977; Berntson et al. 1983; Teich et al. 1988; Romanski and LeDoux 1992). In summary, the Suga model includes the descending auditory system, which is a potential advantage, as its function has been obscure. However, other novel features of this model ignore or are directly contradicted by prior neural and behavioral findings.

\section{Conclusions and future directions}

The major goal of this review has been to explain how a synthesis of the fundamental experimental approaches of two disciplines, sensory neurophysiology and the experimental psychology of learning/memory, can provide a new level of understanding of the neurobiology of associative processes. In particular, the assessment of sensory representations preceding and following standard associative learning tasks (exemplified by classical conditioning) reveals the extent to which resultant neural plasticity is general or specific to signal stimuli, i.e., stimuli that acquire predictive value through learning. The issue of specificity is key to the construct of representation. It is of course important to find that neural plasticity during learning is associative. This type of conclusion has been with us since the dawn of neurophysiological studies of learning and is the starting point for further

\section{Learning \& Memory \\ www.learnmem.org}


inquiry. Beyond associativity is the question of the actual nature of the plasticity, that is, of its essential details, which here are somewhat simplified to general vs. CS-specific modifications of sensory/perceptual neural representations. The use of sensory neurophysiological assessment of receptive fields and functional maps is a first step in revealing the nature and extent to which neural representations undergo modification in learning and memory. In the future it should be possible to similarly interrogate areas other than primary sensory cortices as more is learned about the representations contained therein and the undoubtedly more complex stimulus sets that can probe them.

As discussed previously, many issues could be illuminated by determination of the specificity of plasticity. One not previously mentioned is to determine whether or not a neural change is actually associative. This may seem odd, as heretofore specificity has been treated as the next step beyond associativity. But examination of Figure 7, A and B may prove revealing. Note that Figure 7A shows that responses to the CS frequency are increased when the CS and US are paired. Of note, Figure 7B, which summarizes the effects of unpaired or random presentation of CS and US, shows increased responses to all frequencies, any one of which could be the "CS"; indeed, responses are increased whether the sensitization protocol consists of tone and shock or of a visual stimulus and shock. In fact, prior workers who found increased auditory cortical evoked potentials both during pairing and in a variant of a sensitization protocol concluded that there was no genuine associative plasticity in A1 (Hall and Mark 1967; Mark and Hall 1967); for a more detailed analysis, see Weinberger (1992). It is only by obtaining responses to other frequencies that the true picture emerges. Pairing produces a specific increase at the CS frequency, whereas sensitization protocols produce a general increase in response across the spectrum. In short, as is universally known, but not always at the forefront of research, methods constrain possible results. In this case, probing the auditory cortex only with the stimulus used as the CS can yield only a fragmentary answer to the question of "What changed in the brain?".

The studies on associative representational plasticity in A1 to date are consistent in reporting specific increased responses to conditioned stimuli and decreased responses to most other frequencies. These opposite changes are often sufficiently large to produce shifts of tuning toward or to the frequency of the CS. Moreover, such favored treatment of the CS can produce an expansion of the auditory cortical area that is best tuning to the frequency band containing the CS frequency. However, it is important to note that while behaviorally verified learning to date is linked to ARPs that favor response to the CS value, ARPs ultimately may be found that have other forms. Ohl and Scheich might be proven to be correct, but such findings would not invalidate those reviewed in this study. Rather, they would energize the search for higher-order "rules" and mechanisms that govern the form of ARPs.

Despite the success of research to date, other possibilities must be entertained, lest inquiry become too narrowly focused. The findings so far have concerned measures of the magnitude of response, essentially reflecting the rate of neuronal discharge. Analyses of temporal patterns of neuronal response are less welldeveloped, but ultimately perhaps of equal importance. Indeed, plasticity of temporal parameters of discharge can take place in the absence of any change in the overall rate of discharge (Edeline 2005).

Future studies can involve many variations of the unified experimental design emphasized in this review. The advantages and limitations of several have been presented elsewhere (Weinberger 2004a,b). Recently, Fritz and Shamma have devised an ingenious variation that permits assessment of spectrotemporal receptive fields on a trial-by-trial basis in attention, thus providing a finer temporal grain of the development of plasticity than heretofore available (Fritz et al. 2003, 2005). However, the fundamental approach remains the same: combining sensory neurophysiological assessments with learning and memory paradigms in the study of basic associative processes.

There is currently general agreement that the nucleus basalis cholinergic innervation of the auditory cortex is sufficient to induce ARPs. Furthermore, the NB/ACh system has been linked directly to auditory associative memory. This is a promising start. The future use of post-training pharmacological manipulations, particularly those targeted at specific times in structures of interest, should greatly clarify the sequence and chemical nature of neural processes that transform sensory experiences into enduring memories. Expanded inquiry into the roles of modulators other than ACh is clearly necessary as well.

The study of ARPs is highly relevant to fundamental issues in learning and memory. Several have been discussed earlier, but they do not exhaust the possibilities. Behavioral theories of associative processes usually postulate internal representations of stimuli, events and behavior that become linked in accordance with the tenets of each theoretical formulation. Moreover, these links are often thought to change in strength under specified circumstances. For those behaviorally trained workers who wish to study the nervous system directly, adding some basic sensory physiological techniques to their research will permit them to directly investigate the behavior-level theories. At present, there seems to be no practical limit to the study of ARPs for any type of task or learning, provided that brain responses to stimuli can be detected.

While "growing pains" may be expected in a field that draws workers from different disciplines, erroneous claims are likely to have negative consequences for progress. It is particularly important that more behavioral scientists join the study of associative representational plasticity, because too many studies in this area exhibit fundamental errors in the conception and execution of behavioral training and testing. I can assure readers that the inclusion of sensory physiological concepts and basic techniques is not daunting. In fact, it is easier to accomplish today because off-the-shelf hardware and software are readily available. It is, of course, equally important that more sensory physiologists become better acquainted with issues and methods in learning and memory. These processes invariably affect sensory processing, particular in cortex, so traditional distinctions between the two disciplines no longer suffice. Also, cross-disciplinary collaborations will bear fruit. The ground has been cleared and some promising seeds have been sown. When many more are planted, the harvest promises to be exceptionally bountiful.

\section{Acknowledgments}

We thank Gabriel K. Hui and Jacquie Weinberger for assistance. This research was supported by research grants from the National Institutes of Health/National Institute on Deafness and Other Communication Disorders (NIDCD), DC-02938 and DC-05592 to N.M.W.

\section{References}

Aramakis, V.B., Bandrowski, A.E., and Ashe, J.H. 1997. Muscarinic reduction of GABAergic synaptic potentials results in disinhibition of the AMPA/kainate-mediated EPSP in auditory cortex. Brain Res. 758: $107-117$.

Aramakis, V.B., Bandrowski, A.E., and Ashe, J.H. 1999. Role of muscarinic receptors, G-proteins, and intracellular messengers in muscarinic modulation of NMDA receptor-mediated synaptic transmission. Synapse 32: 262-275.

Ashe, J.H., McKenna, T.M., and Weinberger, N.M. 1989. Cholinergic modulation of frequency receptive fields in auditory cortex: II. 
Frequency-specific effects of anticholinesterases provide evidence for a modulatory action of endogenous ACh. Synapse 4: 44-54.

Bakin, J.S. and Weinberger, N.M. 1990. Classical conditioning induces CS-specific receptive field plasticity in the auditory cortex of the guinea pig. Brain Res. 536: 271-286.

Bakin, J.S. and Weinberger, N.M. 1996. Induction of a physiological memory in the cerebral cortex by stimulation of the nucleus basalis. Proc. Natl. Acad. Sci. 93: 11219-11224.

Bakin, J.S., Lepan, B., and Weinberger, N.M. 1992. Sensitization induced receptive field plasticity in the auditory cortex is independent of CS-modality. Brain Res. 577: 226-235.

Bakin, J.S., South, D.A., and Weinberger, N.M. 1996. Induction of receptive field plasticity in the auditory cortex of the guinea pig during instrumental avoidance conditioning. Behav. Neurosci. 110: $905-913$.

Bandrowski, A.E., Moore, S.L., and Ashe, J.H. 2001. Cholinergic synaptic potentials in the supragranular layers of auditory cortex. Synapse 41: $118-130$.

Bao, S., Chan, V.T., and Merzenich, M.M. 2001. Cortical remodelling induced by activity of ventral tegmental dopamine neurons. Nature 412: 79-83.

Berntson, G.G., Tuber, D.S., Ronca, A.E., and Bachman, D.S. 1983. The decerebrate human: Associative learning. Exp. Neurol. 81: 77-88.

Birt, D. and Olds, M. 1981. Associative response changes in lateral midbrain tegmentum and medial geniculate during differential appetitive conditioning. J. Neurophysiol. 46: 1039-1055.

Birt, D., Nienhuis, R., and Olds, M. 1979. Separation of associative from non-associative short latency changes in medial geniculate and inferior colliculus during differential conditioning and reversal in rats. Brain Res. 167: 129-138.

Bjordahl, T.S., Dimyan, M.A., and Weinberger, N.M. 1998. Induction of long-term receptive field plasticity in the auditory cortex of the waking guinea pig by stimulation of the nucleus basalis. Behav. Neurosci. 112: 467-479.

Brown, M., Irvine, D.R., and Park, V.N. 2004. Perceptual learning on an auditory frequency discrimination task by cats: Association with changes in primary auditory cortex. Cereb. Cortex 14: 952-965.

Cape, E.G. and Jones, B.E. 2000. Effects of glutamate agonist versus procaine microinjections into the basal forebrain cholinergic cell area upon $\gamma$ and $\theta$ EEG activity and sleep-wake state. Eur. J. Neurosci. 12: $2166-2184$.

Christian, K.M. and Thompson, R.F. 2005. Long-term storage of an associative memory trace in the cerebellum. Behav. Neurosci. 119: $526-537$.

Condon, C.D. and Weinberger, N.M. 1991. Habituation produces frequency-specific plasticity of receptive fields in the auditory cortex. Behav. Neurosci. 105: 416-430.

Cruikshank, S.J., Edeline, J.-M., and Weinberger, N.M. 1992. Stimulation at a site of auditory-somatosensory convergence in the medial geniculate nucleus is an effective unconditioned stimulus for fear conditioning. Behav. Neurosci. 106: 471-483.

Detari, L., Rasmusson, D.D., and Semba, K. 1997a. Phasic relationship between the activity of basal forebrain neurons and cortical EEG in urethane-anesthetized rat. Brain Res. 759: 112-121.

Detari, L., Semba, K., and Rasmusson, D.D. 1997b. Responses of cortical EEG-related basal forebrain neurons to brainstem and sensory stimulation in urethane-anaesthetized rats. Eur. J. Neurosci. 9: 11531161.

Deutsch, J.A. 1971. The cholinergic synapse and the site of memory. Science 174: 788-794.

Diamond, I.T. 1985. A history of the study of the cortex: Changes in the concept of the sensory pathway. In Topics in the history of psychology, (eds. G.A. Kimble and K. Schlesinger), Vol. 1, pp. 305-387. Lawrence Erlbaum Associates, Hillsdale, N.J.

Diamond, D.M. and Weinberger, N.M. 1984a. Physiological plasticity of single neurons in auditory cortex of the cat during acquisition of the pupillary dilation conditioned response: II. Secondary field (AII). Behav. Neurosci. 98: 189-210.

Diamond, D.M. and Weinberger, N.M. 1984b. Physiological plasticity of single neurons in auditory cortex of the cat during acquisition of the pupillary conditioned response: II. Secondary field (AII). Behav. Neurosci. 98: 189-210.

Diamond, D.M. and Weinberger, N.M. 1986. Classical conditioning rapidly induces specific changes in frequency receptive fields of single neurons in secondary and ventral ectosylvian auditory cortical fields. Brain Res. 372: 357-360.

Diamond, D.M. and Weinberger, N.M. 1989. Role of context in the expression of learning-induced plasticity of single neurons in auditory cortex. Behav. Neurosci. 103: 471-494.

DiCara, L.V., Braun, J.J., and Pappas, B.A. 1970. Classical conditioning and instrumental learning of cardiac and gastrointestinal responses following removal of neocortex in the rat. J. Comp. Physiol. Psychol.
73: 208-216.

Dimyan, M.A. and Weinberger, N.M. 1999. Basal forebrain stimulation induces discriminative receptive field plasticity in the auditory cortex. Behav. Neurosci. 113: 691-702.

Disterhoft, J.F. and Stuart, D.K. 1976. Trial sequence of changed unit activity in auditory system of alert rat during conditioned response acquisition and extinction. J. Neurophysiol. 39: 266-281.

Duque, A., Balatoni, B., Detari, L., and Zaborszky, L. 2000. EEG correlation of the discharge properties of identified neurons in the basal forebrain. J. Neurophysiol. 84: 1627-1635.

Edeline, J.-M. 1990. Frequency-specific plasticity of single unit discharges in the rat medial geniculate body. Brain Res. 529: 109119.

Edeline, J.-M. 2003. The thalamo-cortical auditory receptive fields: Regulation by the states of vigilance, learning and the neuromodulatory systems. Exp. Brain Res. 153: 554-572.

Edeline, J.-M. 2005. Learning-induced plasticity in the thalamo-cortica auditory system: Should we move from a rate code description to temporal code description? In The auditory cortex: A synthesis of human and animal research (eds. R. König et al.), pp. 365-382. Lawrence Erlbaum Associates, Mahwah, N.J.

Edeline, J.-M. and Weinberger, N.M. 1991. Thalamic short-term plasticity in the auditory system: Associative returning of receptive fields in the ventral medial geniculate body. Behav. Neurosci. 105: 618-639.

Edeline, J.-M. and Weinberger, N.M. 1992. Associative retuning in the thalamic source of input to the amygdala and auditory cortex: Receptive field plasticity in the medial division of the medial geniculate body. Behav. Neurosci. 106: 81-105.

Edeline, J.-M., Dutrieux, G., and Neuenschwander-el Massioui, N. 1988. Multiunit changes in hippocampus and medial geniculate body in free-behaving rats during acquisition and retention of a conditioned response to a tone. Behav. Neural Biol. 50: 61-79.

Edeline, J.-M., Neuenschwander-el Massioui, N., and Dutrieux, G. 1990. Discriminative long-term retention of rapidly induced multiunit changes in the hippocampus, medial geniculate and auditory cortex. Behav. Brain Res. 39: 145-155.

Edeline, J.-M., Hars, B., Hennevin, E., and Cotillon, N. 2002. Muscimol diffusion after intracerebral microinjections: A reevaluation based on electrophysiological and autoradiographic quantifications. Neurobiol. Learn. Mem. 78: 100-124.

Ellinwood, E.H., Cook, J.D., and Wiilson, W.P. 1968. Habituation of evoked response to uniaural clicks. Brain Res. 7: 306-309.

Fritz, J., Shamma, S., Elhilali, M., and Klein, D. 2003. Rapid task-related plasticity of spectrotemporal receptive fields in primary auditory cortex. Nat. Neurosci. 6: 1216-1223.

Fritz, J., Elhilali, M., and Shamma, S. 2005. Active listening: Task-dependent plasticity of spectrotemporal receptive fields in primary auditory cortex. Hear. Res. 206: $159-176$.

Gabriel, M., Saltwick, S.E., and Miller, J.D. 1975. Conditioning and reversal of short-latency multiple-unit responses in the rabbit medial geniculate nucleus. Science 189: 1108-1109.

Gabriel, M., Miller, J.D., and Saltwick, S.E. 1976. Multiple unit activity of the rabbit medial geniculate nucleus in conditioning, extinction, and reversal. Physiol. Psychol. 4: 124-134.

Galambos, R., Sheatz, G., and Vernier, V. 1956. Electrophysiological correlates of a conditioned response in cats. Science 123: 376-377.

Galvan, V.V. and Weinberger, N.M. 2002. Long-term consolidation and retention of learning-induced tuning plasticity in the auditory cortex of the guinea pig. Neurobiol. Learn. Mem. 77: 78-108.

Galvan, V.V., Chen, J., and Weinberger, N.M. 2001. Long-term frequency tuning of local field potentials in the auditory cortex of the waking guinea pig. J. Assoc. Res. Otolaryngol. 2: 199-215.

Gao, E. and Suga, N. 1998. Experience-dependent corticofugal adjustment of midbrain frequency map in bat auditory system. Proc. Natl. Acad. Sci. 95: 12663-12670.

Gilbert, C.D., Sigman, M., and Crist, R.E. 2001. The neural basis of perceptual learning. Neuron 31: 681-697.

Goldstone, R.L., Schyns, P.G., and Medin, D.L. 1997. Perceptual learning. Academic Press, San Diego, CA.

Hall, R.D. and Mark, R.G. 1967. Fear and the modification of acoustically evoked potentials during conditioning. J. Neurophysiol. 30: 893-910.

Hawkey, D.J., Amitay, S., and Moore, D.R. 2004. Early and rapid perceptual learning. Nat. Neurosci. 7: 1055-1056.

He, J. 2003. Corticofugal modulation of the auditory thalamus. Exp. Brain Res. 153: 579-590.

Hennevin, E., Maho, C., and Hars, B. 1998. Neuronal plasticity induced by fear conditioning is expressed during paradoxical sleep: Evidence from simultaneous recordings in the lateral amygdala and the medial geniculate in rats. Behav. Neurosci. 112: 839-862.

Hsieh, C.Y., Cruikshank, S.J., and Metherate, R. 2000. Differential

\section{Learning \& Memory}


modulation of auditory thalamocortical and intracortical synaptic transmission by cholinergic agonist. Brain Res. 880: 51-64.

Huang, C.L. and Winer, J.A. 2000. Auditory thalamocortical projections in the cat: Laminar and areal patterns of input. J. Comp. Neurol. 427: $302-331$

Introini-Collison, I.B. and McGaugh, J.L. 1988. Modulation of memory by post-training epinephrine: Involvement of cholinergic mechanisms. Psychopharmacology 94: 379-385.

Jarrell, T.W., Gentile, C.G., McCabe, P.M., and Schneiderman, N. 1986a. The role of the medial geniculate region in differential Pavlovian conditioning of bradycardia in rabbits. Brain Res. 374: 126-136.

Jarrell, T.W., Romanski, L.M., Gentile, C.G., McCabe, P.M., and Schneiderman, N. 1986b. Ibotenic acid lesions in the medial geniculate region prevent the acquisition of differential Pavlovian conditioning of bradycardia to acoustic stimuli in rabbits. Brain Res. 382: 199-203.

Kaas, J.H. and Hackett, T.A. 2000. Subdivisions of auditory cortex and processing streams in primates. Proc. Natl. Acad. Sci. 97: 1179311799.

Kilgard, M.P. and Merzenich, M.M. 1998a. Cortical map reorganization enabled by nucleus basalis activity. Science 279: 1714-1718.

Kilgard, M.P. and Merzenich, M.M. 1998b. Plasticity of temporal information processing in the primary auditory cortex. Nat. Neurosci. 1: 727-731.

Kilgard, M.P. and Merzenich, M.M. 2002. Order-sensitive plasticity in adult primary auditory cortex. Proc. Natl. Acad. Sci. 99: 3205-3209.

Kilgard, M.P., Pandya, P.K., Vazquez, J., Gehi, A., Schreiner, C.E., and Merzenich, M.M. 2001. Sensory input directs spatial and tempora plasticity in primary auditory cortex. J. Neurophysiol. 86: 326-338.

Kisley, M.A. and Gerstein, G.L. 2001. Daily variation and appetitive conditioning-induced plasticity of auditory cortex receptive fields. Eur. J. Neurosci. 13: 1993-2003.

Konorski, J. 1967. Integrative activity of the brain: An interdisciplinary approach. University of Chicago Press, Chicago, IL.

Kudoh, M., Seki, K., and Shibuki, K. 2004. Sound sequence discrimination learning is dependent on cholinergic inputs to the rat auditory cortex. Neurosci. Res. 50: 113-123.

LeDoux, J.E., Sakaguchi, A., and Reis, D.J. 1983. Subcortical efferent projections of the medial geniculate emotional responses conditioned to acoustic stimuli. J. Neurosci. 4: 683-698.

LeDoux, J.E., Iwata, J., Pearl, D., and Reis, D.J. 1986a. Disruption of auditory but not visual learning by destruction of intrinsic neurons in the medial geniculate body of the rat. Brain Res. 371: 395-399.

LeDoux, J.E., Iwata, J., Pearl, D., and Reis, D.J. 1986b. Disruption of auditory but not visual learning by destruction of intrinsic neurons in the rat medial geniculate body. Brain Res. 371: 395-399.

Lennartz, R.C. and Weinberger, N.M. 1992a. Analysis of response systems in Pavlovian conditioning reveals rapidly vs slowly acquired conditioned responses: Support for two factors and implications for neurobiology. Psychobiology 20: 93-119.

Lennartz, R.C. and Weinberger, N.M. 1992b. Frequency-specific receptive field plasticity in the medial geniculate body induced by Pavlovian fear conditioning is expressed in the anesthetized brain. Behav. Neurosci. 106: 484-497.

Love, J.A. and Scott, J.W. 1969. Some response characteristics of cells of the magnocellular division of the medial geniculate body of the cat. Can. J. Physiol. Pharmacol. 47: 881-888.

Ma, X. and Suga, N. 2005. Long-term cortical plasticity evoked by electric stimulation and acetylcholine applied to the auditory cortex. Proc. Natl. Acad. Sci. 102: 9335-9340.

Mackintosh, N.J. 1974. The psychology of animal learning. Academic Press, New York.

Maho, C., Hars, B., Edeline, J.-M., and Hennevin, E. 1995. Conditioned changes in the basal forebrain: Relations with learning-induced cortical plasticity. Psychobiology 23: 10-25.

Manunta, Y. and Edeline, J.-M. 1997. Effects of noradrenaline on frequency tuning of rat auditory cortex neurons. Eur. J. Neurosci. 9: 833-847.

Manunta, Y. and Edeline, J.-M. 1999. Effects of noradrenaline on frequency tuning of auditory cortex neurons during wakefulness and slow-wave sleep. Eur. J. Neurosci. 11: 2134-2150.

Mark, R.G. and Hall, R.D. 1967. Acoustically evoked potentials in the cat during conditioning. J. Neurophysiol. 30: 875-892.

Marsh, J.T. and Worden, F.G. 1964. Auditory potential during acoustic habituation: Cochlear nucleus, cerebellum, and auditory cortex. Electroencephalogr. Clin. Neurophysiol. 17: 685-692.

McEchron, M.D., McCabe, P.M., Green, E.J., Llabre, M.M., and Schneiderman, N. 1995. Simultaneous single unit recording in the medial nucleus of the medial geniculate nucleus and amygdaloid central nucleus throughout habituation, acquisition, and extinction of the rabbit's classically conditioned heart rate. Brain Res. 682: $157-166$.
McEchron, M.D., Green, E.J., Winters, R.W., Nolen, T.G., Schneiderman, N., and McCabe, P.M. 1996. Changes of synaptic efficacy in the medial geniculate nucleus as a result of auditory classical conditioning. J. Neurosci. 16: 1273-1283.

McKenna, T.M., Ashe, J.H., and Weinberger, N.M. 1989. Cholinergic modulation of frequency receptive fields in auditory cortex: I. Frequency-specific effects of muscarinic agonists. Synapse 4: 30-43.

McLin III, D.E., Miasnikov, A.A., and Weinberger, N.M. 2002. Induction of behavioral associative memory by stimulation of the nucleus basalis. Proc. Natl. Acad. Sci. 99: 4002-4007.

Mesulam, M.-M., Mufson, E.J., Levey, A.I., and Wainer, B.H. 1983. Cholinergic innervation of cortex by the basal forebrain: Cytochemistry and cortical connections of the septal area diagonal band nuclei, nucleus basalia (substantia innominata), and hypothalamus in the rhesus monkey. J. Comp. Neurol. 214: 170-197.

Metherate, R. and Ashe, J.H. 1993. Nucleus basalis stimulation facilitates thalamocortical synaptic transmission in the rat auditory cortex. Synapse 14: 132-143.

Metherate, R. and Ashe, J.H. 1995. Synaptic interactions involving acetylcholine, glutamate, and GABA in rat auditory cortex. Exp. Brain Res. 107: 59-72.

Metherate, R. and Weinberger, N.M. 1989. Acetylcholine produces stimulus-specific receptive field alterations in cat auditory cortex. Brain Res. 480: 372-377.

Metherate, R., Tremblay, N., and Dykes, R.W. 1987. Acetylcholine permits long-term enhancement of neuronal responsiveness in cat primary somatosensory cortex. Neuroscience 22: 78-81.

Metherate, R., Ashe, J.H., and Weinberger, N.M. 1990. Acetylcholine modifies neuronal acoustic rate-level functions in guinea pig auditory cortex by an action at muscarinic receptors. Synapse 6: $364-368$.

Metherate, R., Cox, C.L., and Ashe, J.H. 1992. Cellular bases of neocortical activation: Modulation of neural oscillations by the nucleus basalis and endogenous acetylcholine. J. Neurosci. 12: 4701-4711.

Metherate, R., Kaur, S., Kawai, H., Lazar, R., Liang, K., and Rose, H.J. 2005. Spectral integration in auditory cortex: Mechanisms and modulation. Hear. Res. 206: 146-158.

Miasnikov, A.A., McLin III, D., and Weinberger, N.M. 2001. Muscarinic dependence of nucleus basalis induced conditioned receptive field plasticity. Neuroreport 12: 1537-1542.

Miasnikov, A.A., Poytress, B.S., Chen, J.C., and Weinberger, N.M. 2004 Stimulation of the nucleus basalis that induces behavioral memory in the rat is motivationally neutral. Abstract Viewer/Itinerary Planner, Program No. 207.6. Society for Neuroscience, Washington, D.C.

Miasnikov, A.A., Chen, J.C., and Weinberger, N.M. 2006. Rapid induction of specific associative behavioral memory by stimulation of the nucleus basalis in the rat. Neurobiol. Learn. Mem. 86: 47-65.

Moore, D.R., Amitay, S., and Hawkey, D.J. 2003. Auditory perceptual learning. Learn. Mem. 10: 83-85.

Morris, J.S., Friston, K.J., and Dolan, R.J. 1998. Experience-dependent modulation of tonotopic neural responses in human auditory cortex. Proc. R. Soc. Lond. B. Biol. Sci. 265: 649-657.

Moucha, R., Pandya, P.K., Engineer, N.D., Rathbun, D.L., and Kilgard, M.P. 2005. Background sounds contribute to spectrotemporal plasticity in primary auditory cortex. Exp. Brain Res. 162: 417-427.

Mowrer, O.H. 1947. On the dual nature of learning: A re-interpretation of "conditioning" and "problem-solving". Harv. Educ. Rev. 17: $102-148$.

Norman, R.J., Buchwald, J.S., and Villablanca, J.R. 1977. Classical conditioning with auditory discrimination of the eye blink in decerebrate cats. Science 196: 551-553.

Ohl, F.W. and Scheich, H. 1996. Differential frequency conditioning enhances spectral contrast sensitivity of units in auditory cortex (field Al) of the alert Mongolian gerbil. Eur. J. Neurosci. 8: 10011017.

Ohl, F.W. and Scheich, H. 1997. Learning-induced dynamic receptive field changes in primary auditory cortex of the unanaesthetized Mongolian gerbil. J. Comp. Physiol. [A] 181: 685-696.

Ohl, F.W. and Scheich, H. 2004. Online correspondence: Fallacies in behavioural interpretation of auditory cortex plasticity. Nature Rev. Neuro. http://www.nature.com/nrn/journal/v5/n4/corres/nrn1366_fs. html.

Ohl, F.W. and Scheich, H. 2005. Learning-induced plasticity in animal and human auditory cortex. Curr. Opin. Neurobiol. 15: 470-477.

Ohl, F.W., Deliano, M., Scheich, H., and Freeman, W.J. 2003. Analysis of evoked and emergent patterns of stimulus-related auditory cortical activity. Rev. Neurosci. 14: 35-42.

Oleson, T.D., Ashe, J.H., and Weinberger, N.M. 1975. Modification of auditory and somatosensory system activity during pupillary conditioning in the paralyzed cat. J. Neurophysiol. 38: 1114-1139. 
Palmer, C.V., Nelson, C.T., and Lindley, G.A.T. 1998. The functionally and physiologically plastic adult auditory system. J. Acoust. Soc. Am. 103: 1705-1721.

Pandya, P.K., Moucha, R., Engineer, N.D., Rathbun, D.L., Vazquez, J., and Kilgard, M.P. 2005. Asynchronous inputs alter excitability, spike timing, and topography in primary auditory cortex. Hear. Res. 203: 10-20.

Parsons, R.G., Riedner, B.A., Gafford, G.M., and Helmstetter, F.J. 2006. The formation of auditory fear memory requires the synthesis of protein and mRNA in the auditory thalamus. Neuroscience 141: $1163-1170$.

Pennartz, C.M. 1995. The ascending neuromodulatory systems in learning by reinforcement: Comparing computational conjectures with experimental findings. Brain Res. Brain Res. Rev. 21: 219-245.

Pleger, B., Foerster, A.F., Ragert, P., Dinse, H.R., Schwenkreis, P., Malin, J.P., Nicolas, V., and Tegenthoff, M. 2003. Functional imaging of perceptual learning in human primary and secondary somatosensory cortex. Neuron 40: 643-653.

Polley, D.B., Steinberg, E.E., and Merzenich, M.M. 2006. Perceptual learning directs auditory cortical map reorganization through top-down influences. J. Neurosci. 26: 4970-4982.

Poremba, A. and Gabriel, M. 1997. Medial geniculate lesions block amygdalar and cingulothalamic learning-related neuronal activity. J. Neurosci. 17: 8645-8655.

Rasmusson, D.D., Clow, K., and Szerb, J.C. 1994. Modification of neocortical acetylcholine release and electroencephalogram desynchronization due to brainstem stimulation by drugs applied to the basal forebrain. Neuroscience 60: 665-677.

Rauschecker, J.P. 2003. Functional organization and plasticity of auditory cortex. In The cognitive neuroscience of music (ed. I. Peretz), pp. 357-365. Oxford University Press, London.

Rescorla, R.A. 1988a. Behavioral studies of Pavlovian conditioning. Annu. Rev. Neurosci. 11: 329-352.

Rescorla, R.A. 1988b. Pavlovian conditioning. Am. Psychol. 43: 151-160.

Riquimaroux, H., Gaioni, S.J., and Suga, N. 1992. Inactivation of the DSCF area of the auditory cortex with muscimol disrupts frequency discrimination in the mustached bat. J. Neurophysiol. 68: 1613-1623.

Romanski, L.M. and LeDoux, J.E. 1992. Equipotentiality of thalamo-amygdala and thalamo-cortico-amygdala circuits in auditory fear conditioning. J. Neurosci. 12: 4501-4509.

Rutkowski, R.G. and Weinberger, N.M. 2005. Encoding of learned importance of sound by magnitude of representational area in primary auditory cortex. Proc. Natl. Acad. Sci. 102: 13664-13669.

Rutkowski, R.G., Miasnikov, A.A., and Weinberger, N.M. 2003. Characterisation of multiple physiological fields within the anatomical core of rat auditory cortex. Hear. Res. 181: 116-130.

Schlosberg, H. 1937. The relationship between success and the laws of conditioning. Psychol. Rev. 44: 379-394.

Shulz, D.E., Cohen, S., Haidarliu, S., and Ahissar, E. 1997. Differential effects of acetylcholine on neuronal activity and interactions in the auditory cortex of the guinea-pig. Eur. J. Neurosci. 9: 396-409.

Stark, H. and Scheich, H. 1997. Dopaminergic and serotonergic neurotransmission systems are differentially involved in auditory cortex learning: A long-term microdialysis study of metabolites. J. Neurochem. 68: 691-697.

Suga, N. and Ma, X. 2003. Multiparametric corticofugal modulation and plasticity in the auditory system. Nat. Rev. Neurosci. 4: 783-794.

Teich, A.H., McCabe, P.M., Gentile, C.G., Jarrell, T.W., Winters, R.W., Liskowsky, D.R., and Schneiderman, N. 1988. Role of auditory cortex in the acquisition of differential heart rate conditioning. Physiol. Behav. 44: 405-412.

Teich, A.H., McCabe, P.M., Gentile, C.C., Schneiderman, L.S., Winters, R.W., Liskowsky, D.R., and Schneiderman, N. 1989. Auditory cortex lesions prevent the extinction of Pavlovian differential heart rate conditioning to tonal stimuli in rabbits. Brain Res. 480: 210-218.

Thiel, C.M., Bentley, P., and Dolan, R.J. 2002a. Effects of cholinergic enhancement on conditioning-related responses in human auditory cortex. Eur. J. Neurosci. 16: 2199-2206.

Thiel, C.M., Friston, K.J., and Dolan, R.J. 2002b. Cholinergic modulation of experience-dependent plasticity in human auditory cortex. Neuron 35: $567-574$

Tunturi, A.R. 1944. Audio frequency localization in the acoustic cortex of the dog. Am. J. Physiol. 141: 397-403.

Weber, B.A. 1970. Habituation and dishabituation of the averaged auditory evoked response. J. Speech Hear. Res. 13: 387-394.

Weinberger, N.M. 1982. Sensory plasticity and learning: The magnocellular medial geniculate nucleus of the auditory system.
In Conditioning: Representation of involved neural function (ed. C.D. Woody), pp. 697-710. Plenum Publishing, New York.

Weinberger, N.M. 1992. Beyond neuronal excitability: Receptive field analysis reveals that association specifically modifies the representation of auditory information. In Neuropsychology of memory, 2nd ed. (eds. L. Squire and N. Butters), pp. 496-509. Guilford Press, New York.

Weinberger, N.M. 1998. Physiological memory in primary auditory cortex: Characteristics and mechanisms. Neurobiol. Learn. Mem. 70: $226-251$.

Weinberger, N.M. 2003. The nucleus basalis and memory codes: Auditory cortical plasticity and the induction of specific, associative behavioral memory. Neurobiol. Learn. Mem. 80: 268-284.

Weinberger, N.M. 2004a. Experience-dependent response plasticity in the auditory cortex: Issues, characteristics, mechanisms and functions. In Plasticity of the auditory system (eds. T.N. Parks, E. Rubel, and A. Popper), pp. 173-228. Springer-Verlag, New York.

Weinberger, N.M. 2004b. Specific long-term memory traces in primary auditory cortex. Nat. Rev. Neurosci. 5: 279-290.

Weinberger, N.M. and Diamond, D.M. 1987. Physiological plasticity in auditory cortex: Rapid induction by learning. Prog. Neurobiol. 29: 1-55.

Weinberger, N.M. and Lindsley, D.B. 1964. Behavioral and electroencephalographic arousal to contrasting novel stimulation. Science 144: 1355-1357.

Weinberger, N.M., Oleson, T.D., and Ashe, J.H. 1975. Sensory system neural activity during habituation of the pupillary orienting reflex. Behav. Biol. 15: 283-301.

Weinberger, N.M., Diamond, D.M., and McKenna, T.M. 1984a. Initial events in conditioning: Plasticity in the pupillomotor and auditory systems. In: Neurobiology of learning and memory (eds. G. Lynch, J.L. McGaugh, and N.M. Weinberger), chap. 12, pp. 197-227. Guilford Press, New York.

Weinberger, N.M., Hopkins, W., and Diamond, D.M. 1984b. Physiological plasticity of single neurons in auditory cortex of the cat during acquisition of the pupillary conditioned response: I. Primary field (AI). Behav. Neurosci. 98: 171-188.

Weinberger, N.M., Ashe, J.H., Metherate, R., McKenna, T.M., Diamond, D.M., and Bakin, J.S. 1990a. Retuning auditory cortex by learning: A preliminary model of receptive field plasticity. Concepts Neurosci. 1: $91-131$.

Weinberger, N.M., Ashe, J.H., Metherate, R., McKenna, T.M., Diamond, D.M., Bakin, J.S., Lennartz, R.C., and Cassady, J.M. 1990b. Neural adaptive information processing: A preliminary model of receptive field plasticity in auditory cortex during Pavlovian conditioning. In Neurocomputation and learning: Foundations of adaptive networks (eds. M. Gabriel and J. Moore), pp. 91-138. Bradford Books/MIT Press, Cambridge, MA

Weinberger, N.M., Javid, R., and Lepan, B. 1993. Long-term retention of learning-induced receptive-field plasticity in the auditory cortex. Proc. Natl. Acad. Sci. 90: 2394-2398.

Weinberger, N.M., Javid, R., and Lepan, B. 1995. Heterosynaptic long-term facilitation of sensory-evoked responses in the auditory cortex by stimulation of the magnocellular medial geniculate body in guinea pigs. Behav. Neurosci. 109: 10-17.

Weinberger, N.M., Miasnikov, A.A., and Chen, J.C. 2006. The level of cholinergic nucleus basalis activation controls the specificity of auditory associative memory. Neurobiol. Learn. Mem. 86: 270285.

Wepsic, J.G. 1966. Multimodal sensory activation of cells in the magnocellular medial geniculate nucleus. Exp. Neurol. 15: 299-318.

Westenberg, I.S. and Weinberger, N.M. 1976. Evoked potential decrements in auditory cortex. II: Critical test for habituation. Electroencephalogr. Clin. Neurophysiol. 40: 356-369.

Wickelgren, W.O. 1968. Effect of acoustic habituation on click-evoked responses in cats. J. Neurophysiol. 31: 777-785.

Winer, J.A. and Morest, D.K. 1983. The medial division of the medial geniculate body of the cat: Implications for thalamic organization. J. Neurosci. 3: 2629-2651.

Yu, Y.Q., Xiong, Y., Chan, Y.S., and He, J. 2004. Corticofugal gating of auditory information in the thalamus: An in vivo intracellular recording study. J. Neurosci. 24: 3060-3069.

Received August 31, 2006; accepted in revised form October 20, 2006 


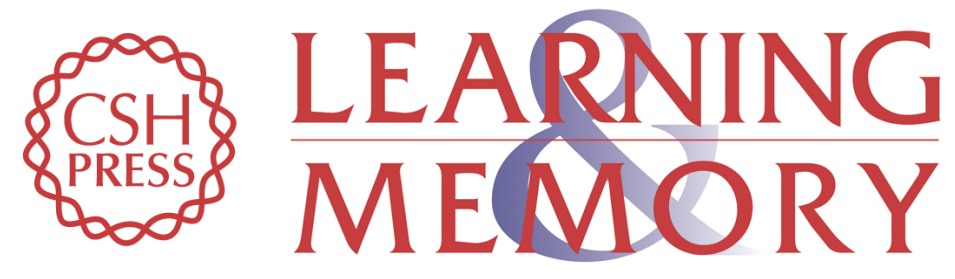

\section{Associative representational plasticity in the auditory cortex: A synthesis of two disciplines}

Norman M. Weinberger

Learn. Mem. 2007, 14: originally published online January 3, 2007

Access the most recent version at doi:10.1101//m.421807

References This article cites 139 articles, 22 of which can be accessed free at:

http://learnmem.cshlp.org/content/14/1-2/1.full.html\#ref-list-1

License

Email Alerting Receive free email alerts when new articles cite this article - sign up in the box at the Service top right corner of the article or click here. 